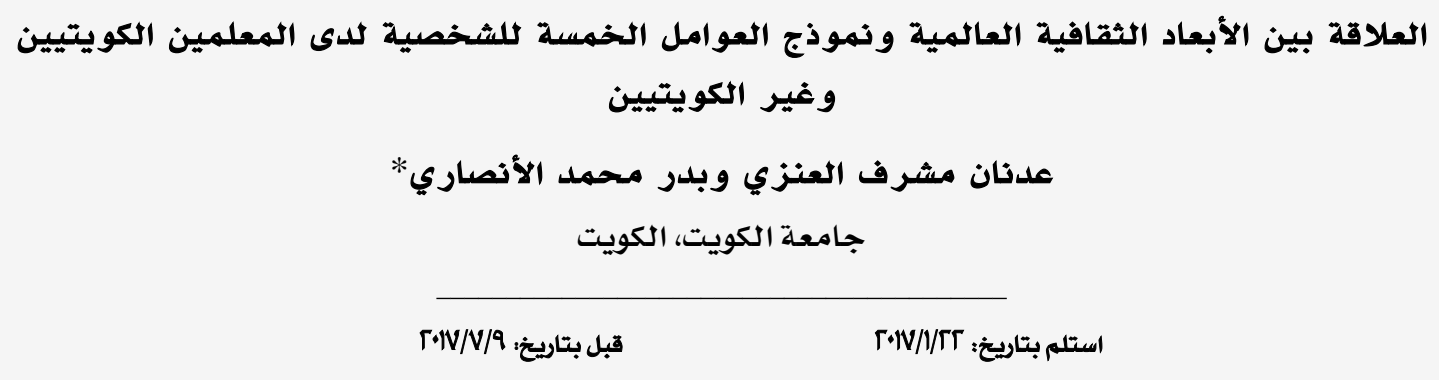

ملخص: هدفت الدراسة إلى بحث العلاقة بين الأبعاد الثقافية العالمية والعوامل الخمسة للشخصية لدى عينة قوامها •^••1 معلما من

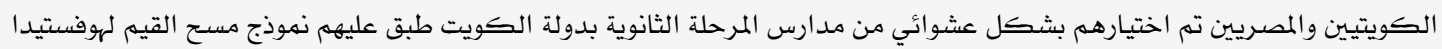

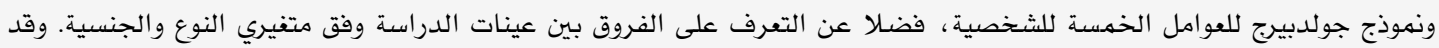

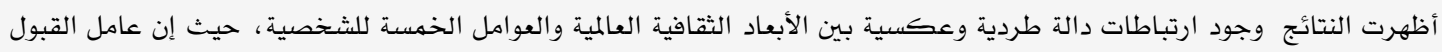

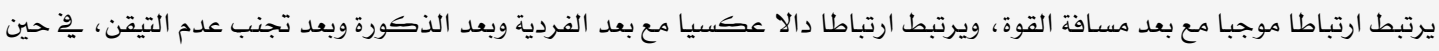

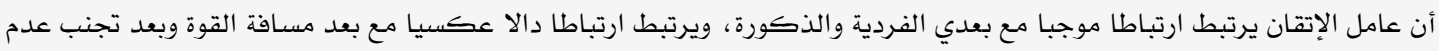

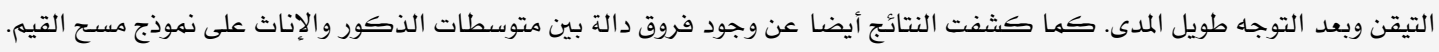

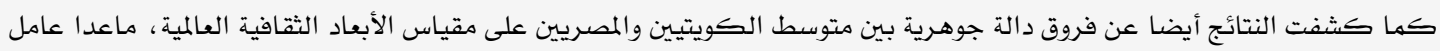
بعد التوجه طويل المدى. كلمات مفتاحية: الأبعاد الثقافية العالمية ، العوامل الخمسة للشخصية، الكويت، المعلمين.

\title{
Relationship between Dimensions of International Culture and the Five-Factor Model of Personality for Kuwaitis and Non-Kuwaiti Teachers
}

Adnan M. Alanzi \& Bader M. Alansari* University of Kuwait, Kuwait

\begin{abstract}
This study aimed to examine the relationship between the dimensions of international culture and the five factors of personality in a sample of 1080 Kuwaiti and Egyptian teachers which was selected randomly from secondary schools in Kuwait, measured by Hofstede's five cultural dimensions and five-factor model; gender and nationality were also considered. The results indicated significant positive correlations between agreeableness and power distance, conscientiousness and both individuality and masculinity. There are also significant negative correlations between agreeableness and each individuality and masculinity and uncertainty avoidance, conscientiousness and the variable of power distance, uncertainty avoidance and long-term trend. Also, the results showed that males differed from females on four out of the five cultural dimensions. However, Kuwaitis differ from Egyptians on four out of the five cultural dimensions. Except in the long-term trend, there were no significant differences between the Kuwaitis and Egyptians.
\end{abstract}

Keywords: Dimensions of international culture, five-factor model of personality, Kuwait, teachers.

\section{*baderansari@gmail.com}


عنيفة في بعض الحالات، و لا تتغير الشخصية

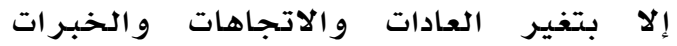
وطرق التفكير، ويكون التغير في الشخصية

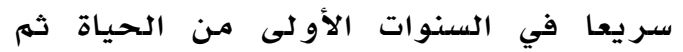

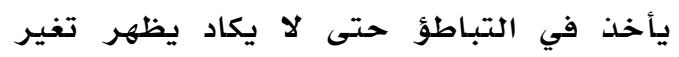
ملحوظ في مرحلة الرشل. و تغير الشخصية قد يحدث بقصد من الإنسان، أو دون قصد إند منـه. مـن أجل ذلك بحل كله ارتبطت الثقافة

بالشخصية (Kashima, \& Kashima, 2003). و لتحديد الجوانب أو الأبعاد الثقافية للإفر اد قام هوفستيدا (Hofstede, 1984) بإجر اء مستح للبيانات حول تلك الأبعاد الثقافية العالمية Dimensions of International Culture في أكثر من له بلدا في جميع أنحاء العالم في الفروع المهلية لشركة ( International (Business Machines -IBM الجنسيات (Hofstede, 1984). حيث تم إعطاؤه

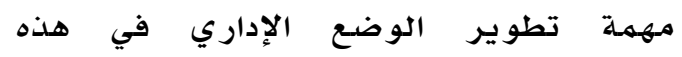
الشركة عن طريق تحسين أداء العاملين في الثري الشركة مـن خلال بر نامج دراسة التجاهات

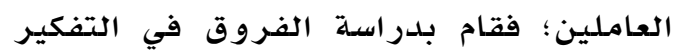

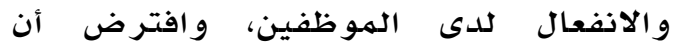

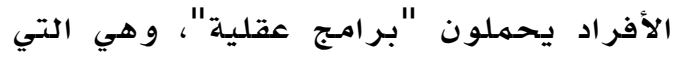

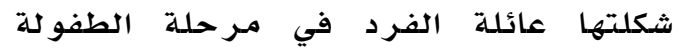

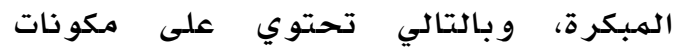
الثقافة الوطنية، فقد كان اهتمام المديرين

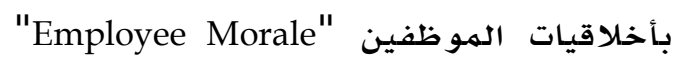

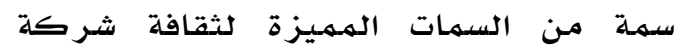

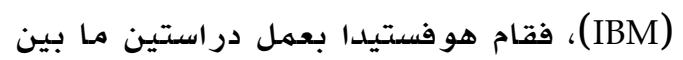

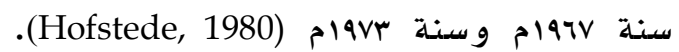
وكان الاستبيان الخاص بدراسته يحتوي

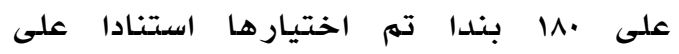
مقابلات مفتوحة جرت في مكاتب الشركة، وكان أول إعداد للاستبيان في يناير لوجام،

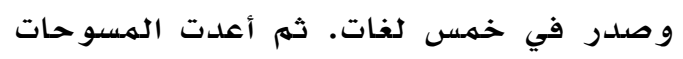

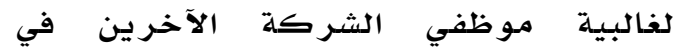
نوفمبر عام 197Vم، و صدررت في لغات إضافية

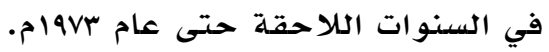
ثم سعى فريق العمل مـن الباحثين لتحسين

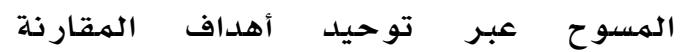

العالم مليء بالمواجهات بين الأفر اد و الجماعات الذين يعتقدون ويشعرون ويسلكون على نحو مختلف. و في الوقت ذاته، فإن هؤلاء الأفراد والجماعات مطلوب منهم التعاون لوضع حلول للمشكلات المشتركة التي يتعرضون لها. فهناك مشكلات بيئية

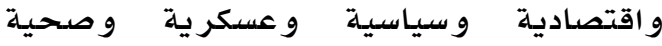

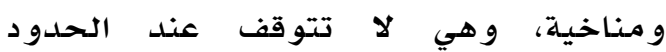
الوطنية أو الإقليمية وتتطلب وهلب التعاون من قادة الر أي في العديد من البلديدان، وهؤلاء

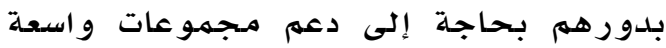

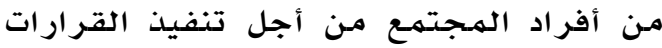

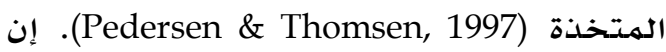
الفروق في أسلوب التفكير والانفعال عند هؤلاء القادة وشعوبهم، هو شوط لتحقيق لتحقيق

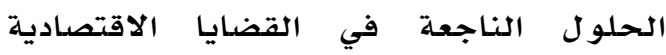
و التكنو لوجية و الطبية.

و لكي نستطيع التعامل مـع الفروق في أساليب التفكير و الانفعال و السلوك كن عند

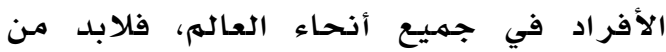

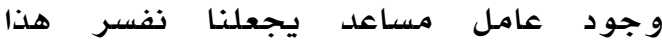

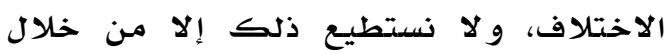
الفهم الواضح لثقافات هؤلاء الأفراد. فالهدف من النظريات التي تناولت الثقافة هو تفسير التباين بين الأفراد في المعرفة فئس الاجتماعية

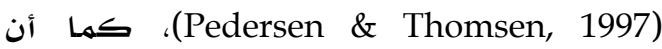
ثقافة المجتمـع تؤثر في شخصية الأفراد

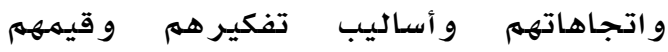

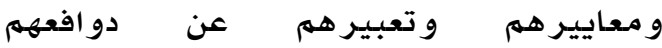

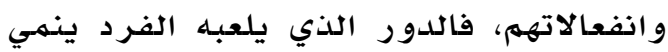
سمات معينة في شخصيته و ويهحو سهمات أخرى، كما أن عجز الفرد عن القيام بلدوره يمس عاطفة احتر امه لذاتله، مـما قد يعرض شخصيته لاضطراب، ويندر أن يقوم الفرد بلدور واحد، بل إنه في الغالب يلعب عدة أدوار في الوقت نفسـه، وقد يحصل صراع بين تلك الأدوار، وانتقال الفرد إدواد دهولى دور جديد من شأنه أن يجعله يتنازل عن عن عادات

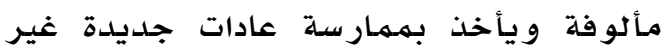

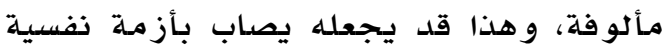


- Multidimensional Model of Personality قام كاتل (Cattell, 1943) بمر اجعة قائمة

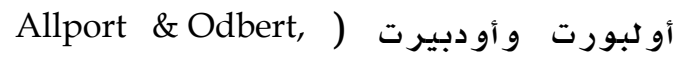

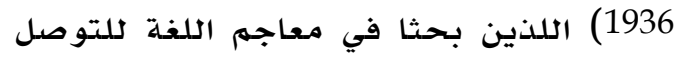

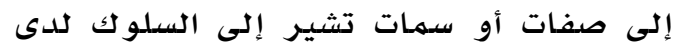

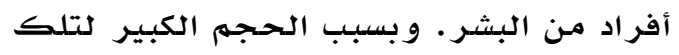

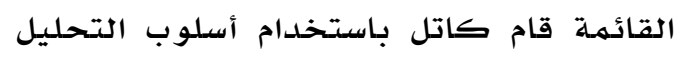

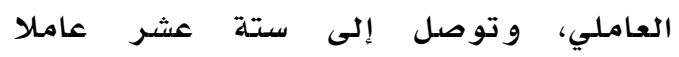
للشخصية (16 Personality Factors - 16PF)

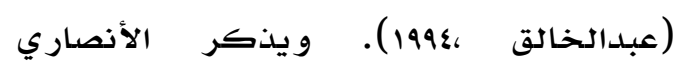

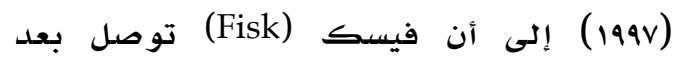
ذلك إلى استخراج خمسة عوامل إنى للشخصية

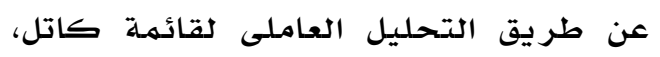

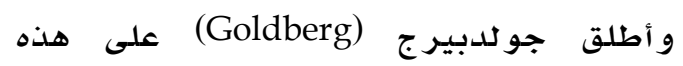

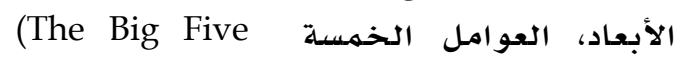
(Factors -BFF)

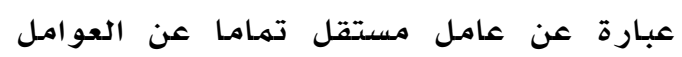

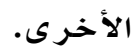

كما قام أيضا كوستا وماكرى ( Costa \&

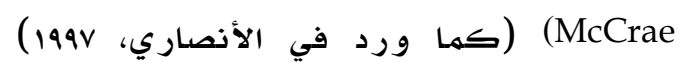

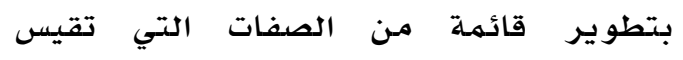

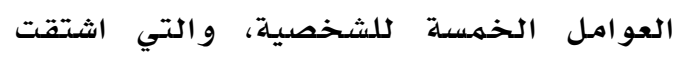

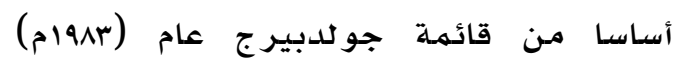

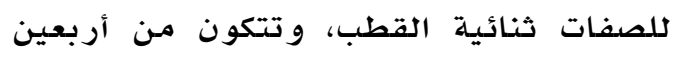
صفة، وقد أضافا إليها ضعف هذا العة العدد من آندان

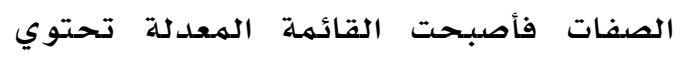

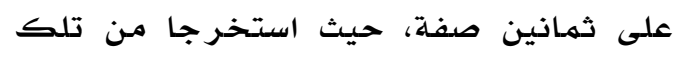

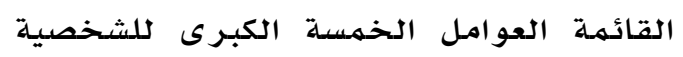

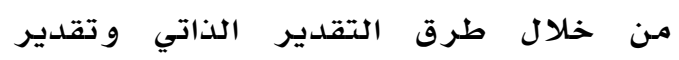

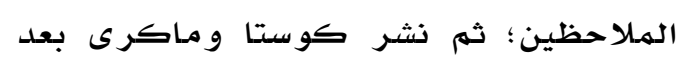

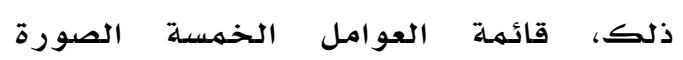
المختصرة (NEO-FFI) و تحتوي على لج لج بندا في أصلها الإنجليزي عام (919ام)، ثم صدري علدرت

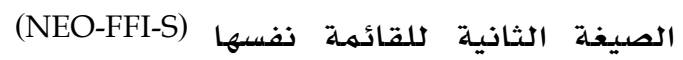
عام (1999م). ويبرز الأنصاري (199v) أهمية

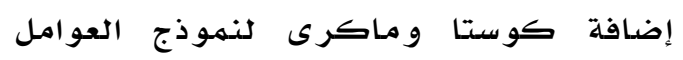

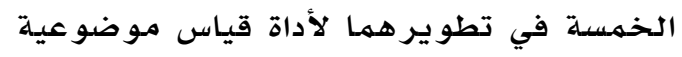
تقيس العوامل الأساسية الكبرى للشخصية لهوبية

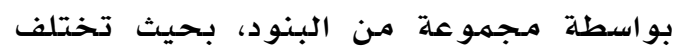
طريقتهما عن مناهج الدراسات الأخرى التئي
والمرونة لحصر المؤهلات للاحتياجات المحلية باستخدام التحليل العاملي. ونتيجة لذلك تم تخفيض الاستبيان إلى مجموعة

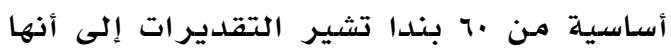

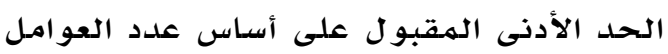

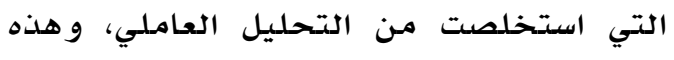

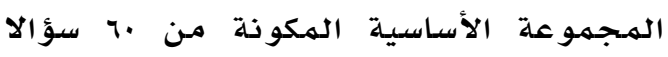

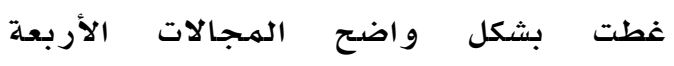

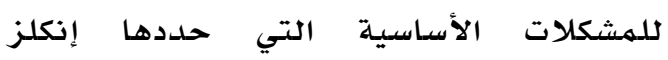
و ليفنسن (Inkeles \& Levinson, 1954) قبل الأني عاما و التي تمثل أبعاد الثقافات. و هذه الأبعاد

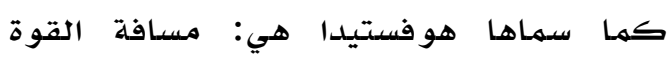

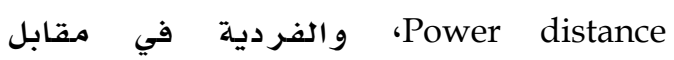
الجماعية (Individualism vs. Collectivism)، والذكورة في مقابل الأنوثة ( Masculinity vs. Femininity

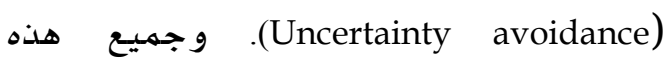
الأبعاد موجودة بالفعل في جزء من العاء العلوم

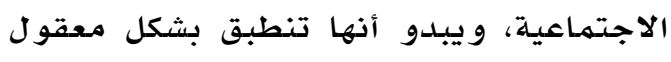

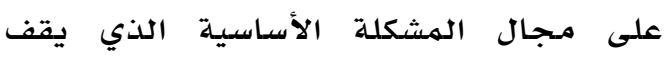

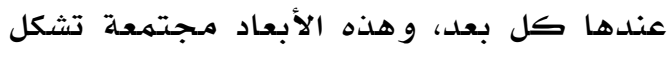

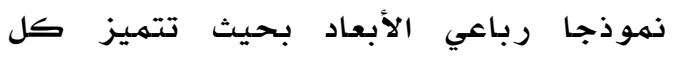
ثقافة بدرجة في كل بعد من الأبعاد الأربعة (Davies, \& Ellis, 2000). و في الآونة في الأخيرة،

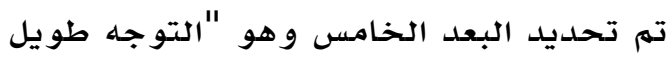

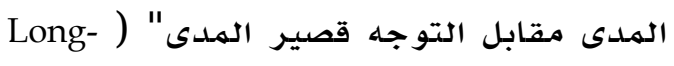
(term vs. Short-term Orientation للاختلافات بين الثقافات الوطنية، وذلك

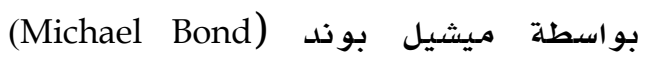

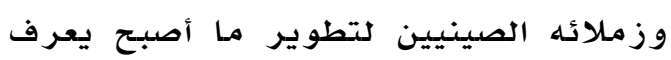
Chinese Value ( باستبيان "القيم الصينية .(Survey - CVS أما بالنسبة للشخصية، فقد أيقن علماء نفس

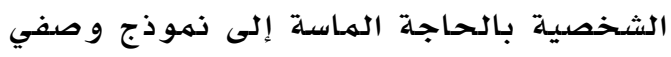
أو تصنيف يشكل الأبعاد أو العوامل الأساسية الف ذهودية

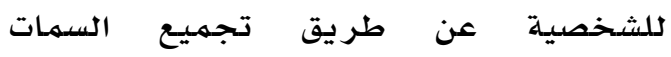

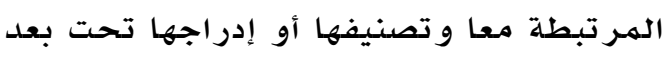

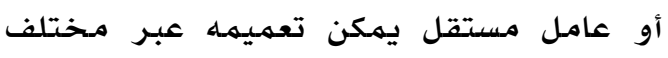

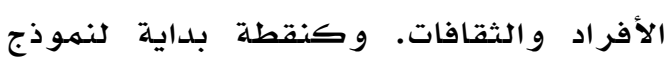

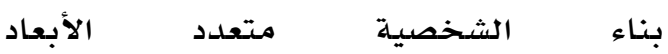




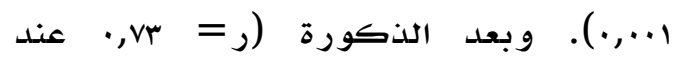

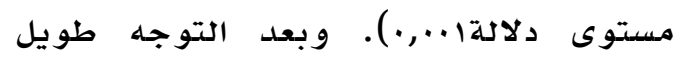

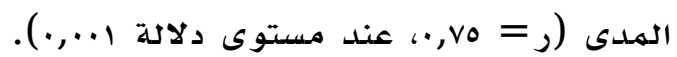
كما أن بعد الفردية ير تبط ارتباطا جوهريا

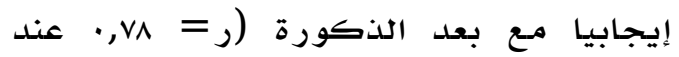

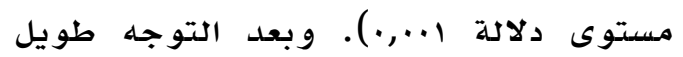

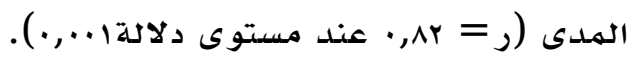

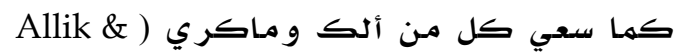

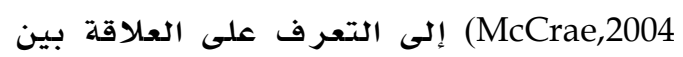
عاملي العصابية والانبساطية باستخدام قائمهة

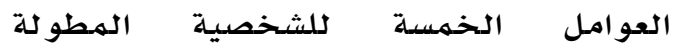
Revised NEO Personality Inventory-) N N N N N N الأبعاد الثقافية العالمية

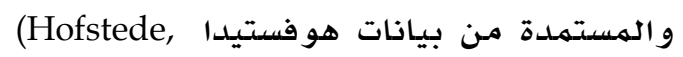
(2001 التي استخدمت مقياس مستح القيه

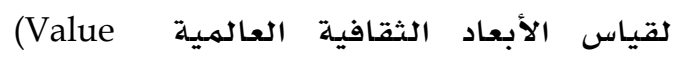

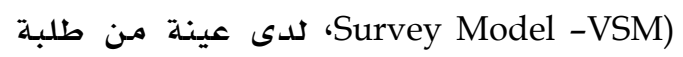
الجامعات قوامها (rVq70) فر دا في (rro) دو للة،

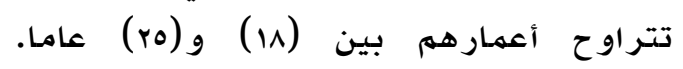
و أظهرت النتائج أن العصدابية ترتبط ارتباطا لئار

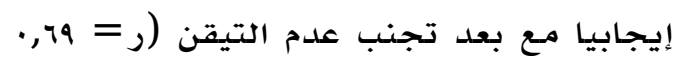

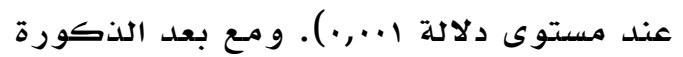

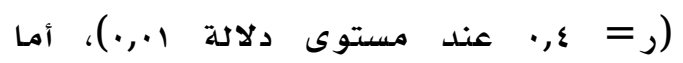

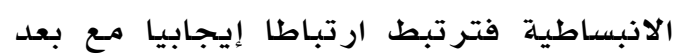

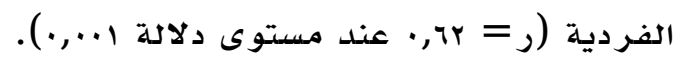

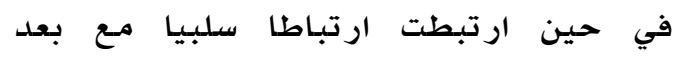

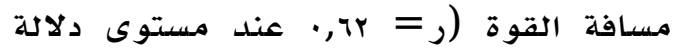
.$(\cdot, \cdots)$

ثانيا: دراسـات ثقافية مقارنة عن الأبعاد الثقافية العالميلة.

و تهدف دراسة ذوموف وبوفر ( Naumov \&

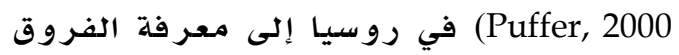
بين نتائج دراسـة هوفستيدا (Hofstede, 1993) ودراستهما باستخدام مقياس مستح موله القيه

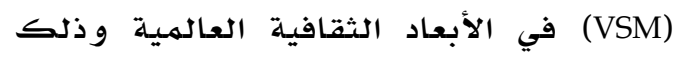

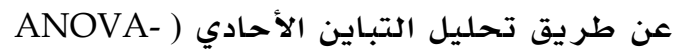
(Unequal Variables

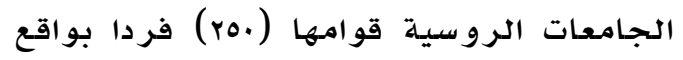

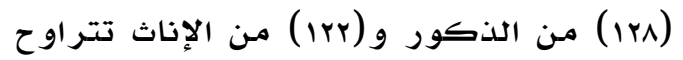

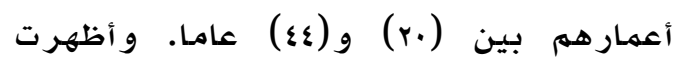

اعتمدات أساسا على منهج الهفردات اللغوية المشتقة من معاجم اللغة.

وفيما يتعلق بالدراسات السابقة التي تناولت

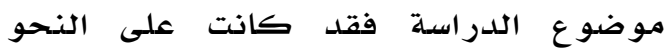

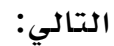

أو لا: دراسات ثقافية مقارنة عن العلاقة بين

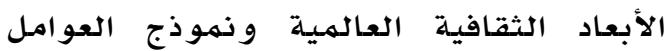
الخخمسة للشخصية:

(Lynn \& Martin, تهدف دراسة لين وومارتن

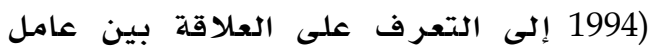
العصابية و بعد تجنب عدم التيقن، وذلك من الكن

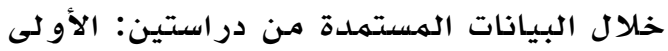

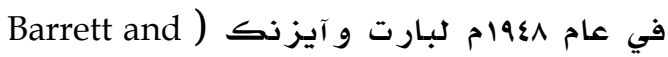

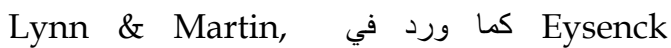
(1994,p.403 (Eysenck Personality

للشخصية عبر Qu دو لة. و الثانية Questionnaire-EPQ)

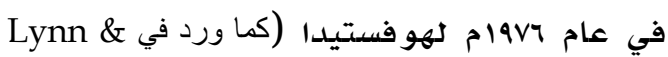

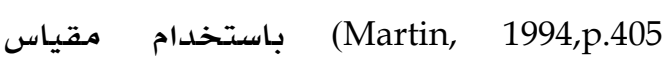
هو فستيدا للقلق (Hofstede anxiety scores)

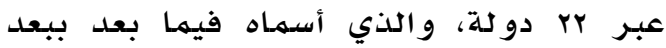

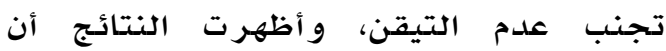
العصابية ترتبط ارتبطا إيجابيا مـع بعد بعد

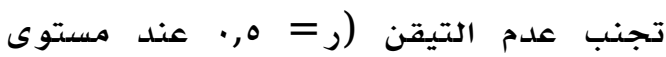
دلالة ه., (•).

Ardichvili \& أما دراسـة أردشفلي و كشنك (Kuchinke, 2002) التعرف على العلاقة بين الأبعاد الثقافية العالهية (ماعدا بعد تجنب عدم الندام التيقن)، وذلك باستخدام مقياس مستح القيم لقياس

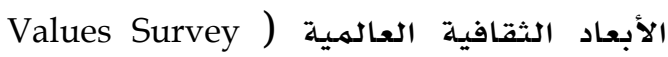
(Module-VSM 94 موظفا إداريا وغير إداري في منظمات

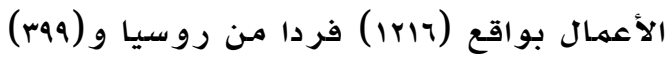

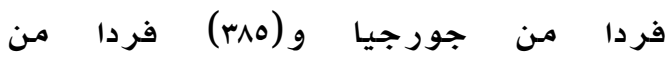

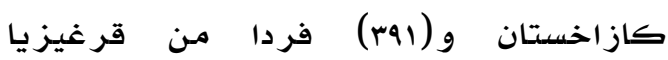

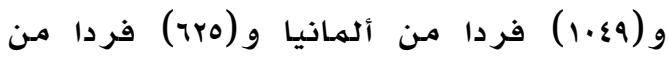
الولايات المتحدة. وأظهرت النتائج أن بعد الهد مسافة القوة يرتبط ارتباطا جوهر يا إيجابيا

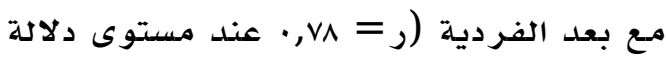


قام كل من ستل وتل (Stull \& Till, 1995) بدر اسة تهدف إلى التعرف على الفروق بين الجنسين

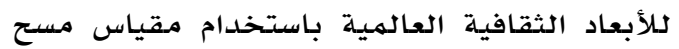
القيه (VSM) لدى عينة من طلاب جامعة "سانت التادئ

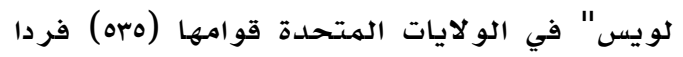

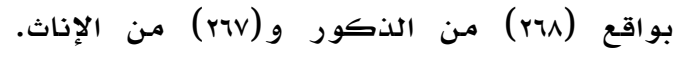

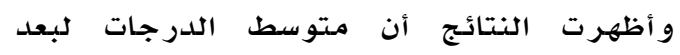

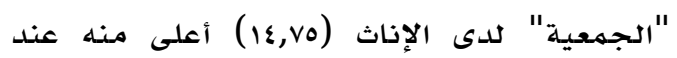

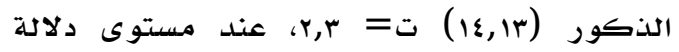

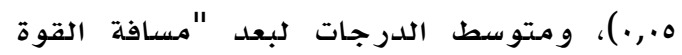

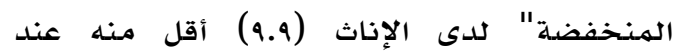

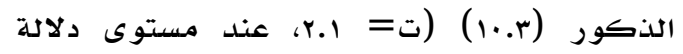

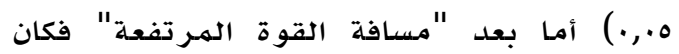

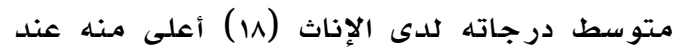

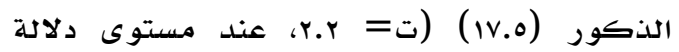

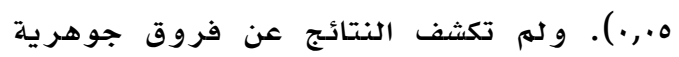
بين الذكور والإناث في بقية الأبعاد (مستوى الدلالة أكبر من ه.,.). و تهدف دراسة كل من فانس وسيفرت و فرانكو وبوف (VanNess, Seifert, Franko \& Buff, 2005) إلى التعرف على الفروق بين الجنسين أيضا في

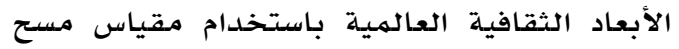
القيم (VSM) لدى عينة من طلاب كليات إدارة

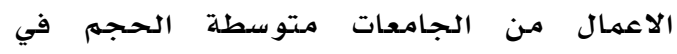
الجنوب الشرقي للولايات المتحدة الأمريكية

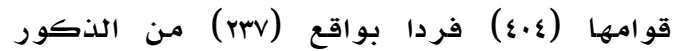

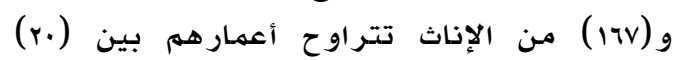

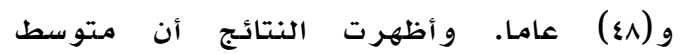

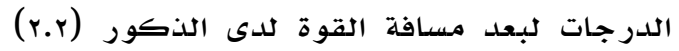

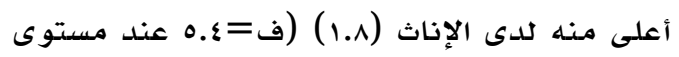

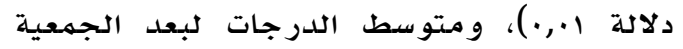

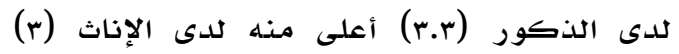

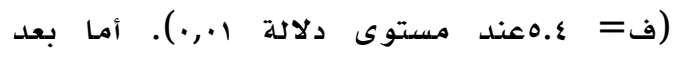
الذكورة فكان متوسط الدرجات لدى الدان الذكور

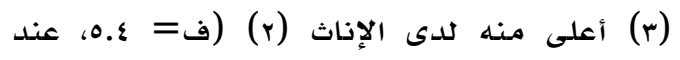

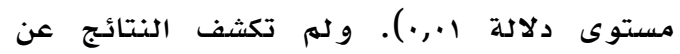
فروق جوهرية بين الذكور والإناث في بقية الأبعاد (مستوى الدلالة أكبر من هـ, بـ). تعقيب على الدر اسـات السـابقة • لم تتناول أية دراسة الأبعاد الثقافية العالمية لدى المعلمين بوجه عام.
النتائج فروقا جوهرية بين أبعاد دراستهما و دراسـة هوفستيدا في بعد مسـافة القوة حيث

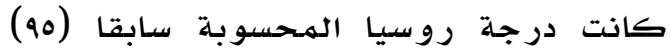

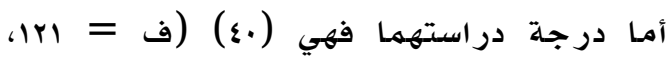

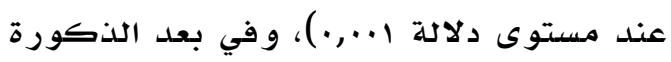

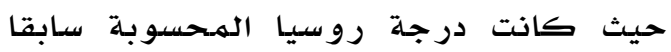

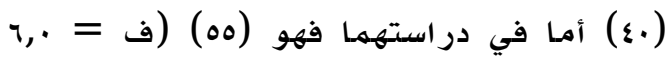

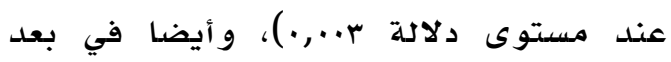
تجنب عدم التيقن حيث كانت درجة روسيا

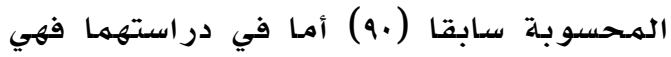

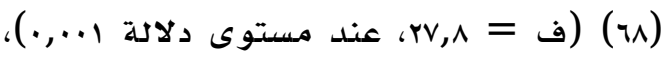
ولم تكثف النتائج عن فروق جوهرية في بعد الفردية (مستوى الدلالة أكبر من من فئن $\cdot(\cdot, 0$

كما أجرى هوفستيدا (Hofstede, 2001b) دراسـة كانت تهدف إل التعرف على الأبعاد

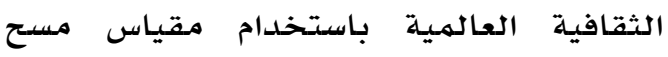
القيم (VSM82)، للدى عينة من الدول لهيه العربية شملت مصر و العر اق و الكويت و لبنان و ليبيا

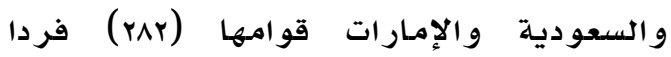

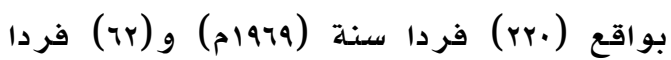

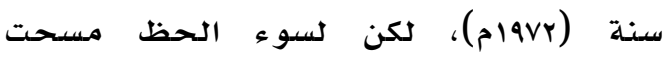
البيانات الخاصدة بكل دولة وتم الاحتفاظ بالبيانات الكلية لهمجموع الدول السبعـ؛ فتم السم

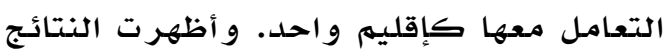

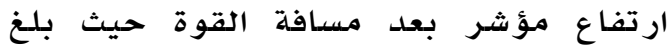

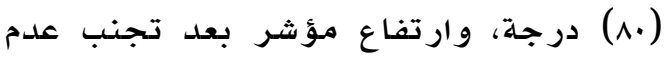

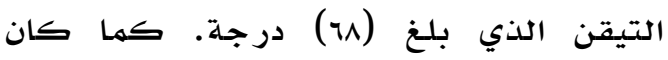

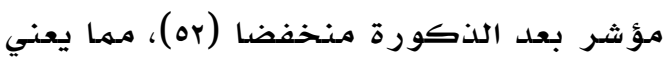
تقاربا بين قيم الرجال و والنساء في هذه هذه

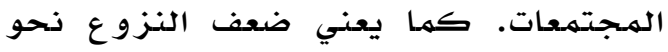
الهيمنة و التملك و التنافس. و وكان مؤشر

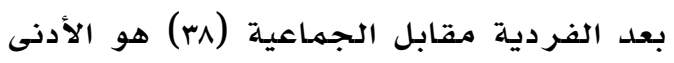

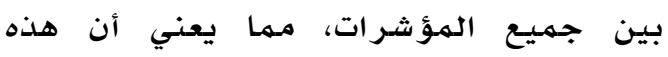

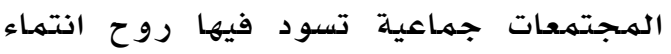
الفرد للمججتمـع وو لائه له. ثالثا : دراسات في الفروق بين الذكور والإناث في الأبعاد الثقافية العالمية. 
أهمية الدراسة

تتلخص الأهمية النظرية للدراسـة في تجسير الفجوة في الدراسات السابقة بطرحها أسلوبا لهابها جديدا نسبيا ومقياسا لهم يتهم التطرق لله بشكل تفصيلي في التراث النفسي العربي، وهى الأبعاد الثقافية العالمية - حيث تعدي الثرية

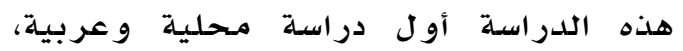

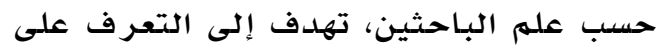

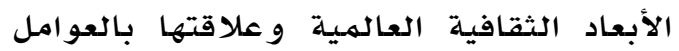
الخمسـة للشخصية لدى عينة من المعلمين الكويتيين و المصريين الذكور والإناث في الذيك

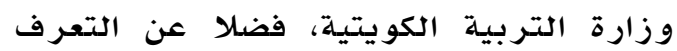

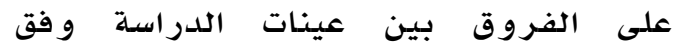

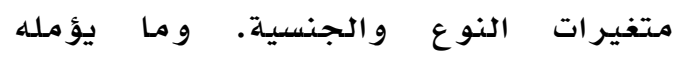

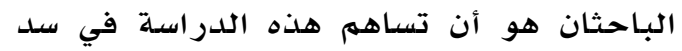

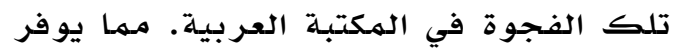
للباحثين و لصانعي القرارات بيانات و اقعية

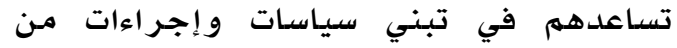

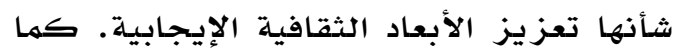
ستسهم هذه الدراسة عن طريق التوصيات

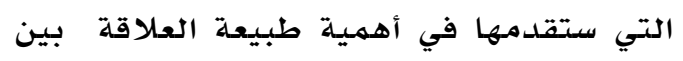
العوامل الخمسـة والأبعاد الثقافية العالمية. كما توفر هذه الدر اسـة نتائج يمكن مقار نتها

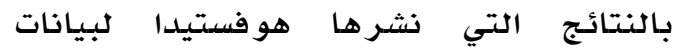

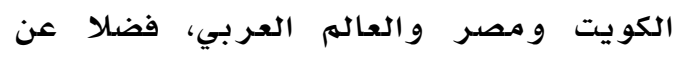

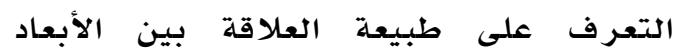

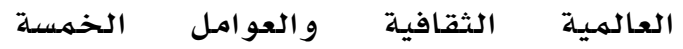

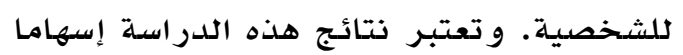
نظريا يمكن أن يساعد على استثارة الباحثين

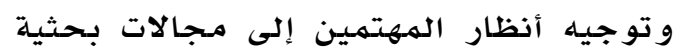

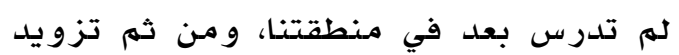
المكتبـة العربية بدراسلة تمثل إطارا نظريا

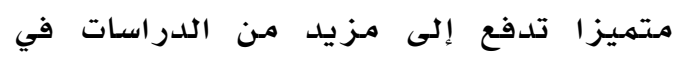

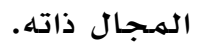
التعر يفات الاجر ائية للمصطلحات الأبعاد الثقافية العالمية: اقترح هوفستيدا خمسة أبعاد يمكن من خلالها تحليل القيه

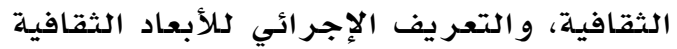

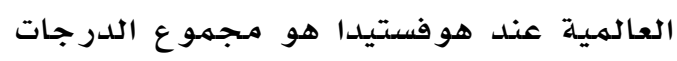

• قلة الدراسات التي تناولت بعد التوجه طويل الأمد في مقابل قصير الأمد.

مشكلة الدراسة

المشكلة الاساسية في الدراسلة تكمن في أنه لهم يتم تقديم الأبعاد الثقافية العالمية من فن قبل في الوطن العربي وخصوسا في الكويت، و أيضدا في عدم توافر بيانات بحثية غير فير

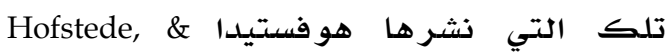
عن البيلاد العربية، ودون (Hofstede, 2013) و جود مرجع يمكن التحقق منه. و وتحاول الدراسة الحالية الإجابة على على التساؤلات الآتية:

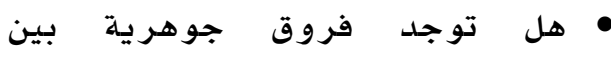

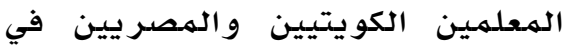
الأبعاد الثقافية العالميلة.

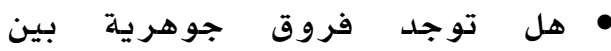
الذكور والإناث في الأبعاد الثقافية العالمية. هل توجد علاقة بين الأبعاد الثقافية العالمية والعوامل الخمسية للشخصية.

فروض الدراسة في ضوء الدر اسـات السـابقة و أهداف البحث تم صياغة فروض الدراسة على النحو الآتي: 1. متوسط الأبعاد الثقافية العالهية لدى

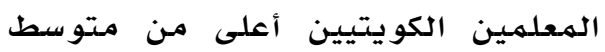

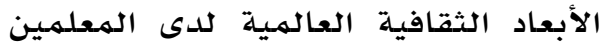
الهصر يين. Y. متوسط الأبعاد الثقافية العالهية لدى

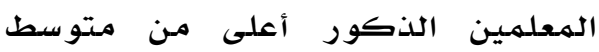
الأبعاد الثقافية العالمية لدئ لدى الهعلمـات الإناث. r. توجد علاقة ارتباطية موجبة ذات دلالة إحصائية بين الأبعاد الثقافية العالميلة

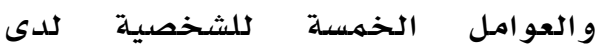
الهعلمين الكويتيين و الهصر يين. 
إلى تجنب التعرض لمثل هذه الهواقف من خلال الحفاظ على قواعد سلوكية

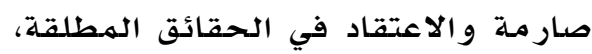

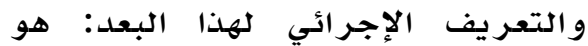
مجموع الدرجات التي يحصل عليها الفرد في البنود التي يمثلها هذا البعد في مقياس مستح القيه لقياس الأبعاد

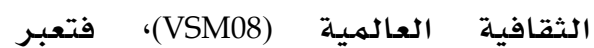

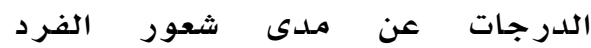

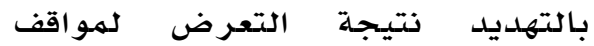
غامضدة أو ضاغطة انفعاليا. Masculinity vs. الذكورة مقابل الأذوثة :Femininity معني بقياس المسافة بين القيم السـائدة

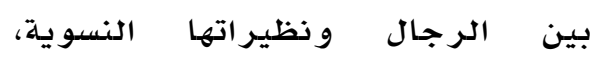
فالاختلافات في قيم الرجال تتراوح بين توكيد الذات أو الهيمنة والتملك والتنافس الشديد من أجل الإنجاز في لون جانب، وبين العطف و التواضـع والإيثار

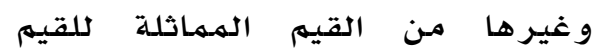

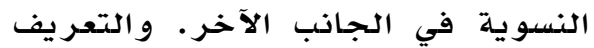

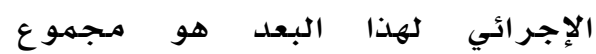
الدرجات التي يحصل عليها الفرد في

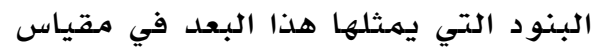
مست القيم لقياس الأبعاد الثقافية

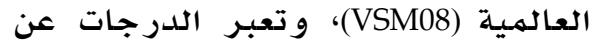

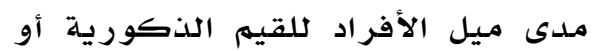
للقيم الأنثوية.

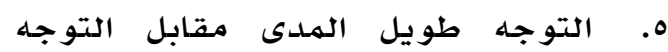

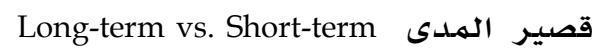
(Barney, ) و ويعرف :orientation

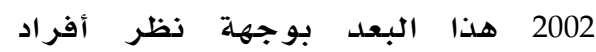

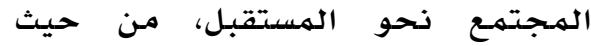

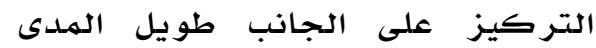
وتقبلهم للتغيير في مقابل التركيز على الجانب قصير المدى من خهل خلال تمسكهم بالجوانب التقليدية و اعتز ازهم همئيل

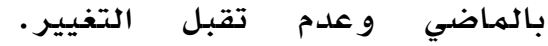

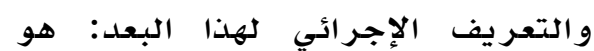

التي يحصل عليها الفرد على كل بعد على حدة في مقياس مستح القيم لقياس الأبعاد الثقافية العالمية (VSM08) و هي كالآتي: 1. مسافة القوة (الاتجاه نحو السلطة) (Hofstede, 2011) يعرف :Power distance بعد مسافة القوة بتفاوت درجة الأفراد

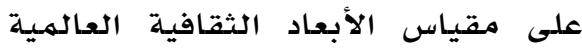
في تقبل المعايير و النظم السـائدة داخل نسق الجماعة ومؤسساتها التتظيمية

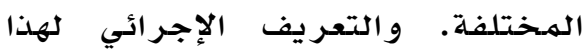
البعد: هو مهجموع الدررجات التي يحصل عليها الفرد في البنود التي يمثلها هذا البعد في مقياس مستح القيم

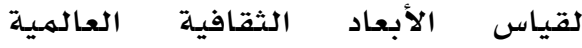

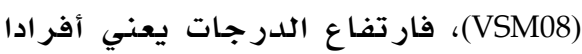
يتسمون بارتباطهم الشديد بكل الأنماط لرهاط السلطوية السـائدة، منخفضي الدرجة يتميزون بعكس هذه

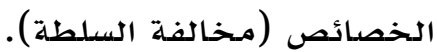
Individualism الفردية مقابل الجماعية (Barney, 2002) و يعرف :vs. Collectivism هذا البعد بمتصل يمتد طرفه الأول إلى ئى ما يسمى بالفردية، ويعنى بزيادة

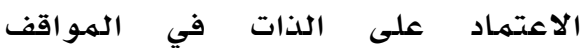

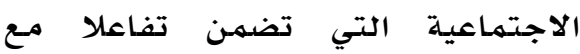

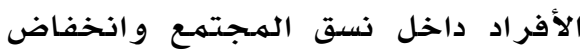
مؤشر الترابط والتعاون مـع الآخر ين.

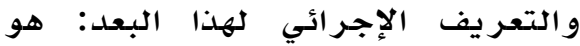
مجمهوع الدرجات التي يحصل يحل عليها الفرد في البنود التي يمثلها هذا البعد البداب في مقياس مستح القيهم لقياس الأبعاد

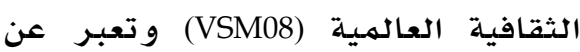
مدى اندماج الفرد في إطار الجماعة. r. تجنب عدم التيقن (تجنب المجهول) (Jandt, و: ويعر ف: Uncertainty avoidance 2009 هذا البعد بأنه متغير معرفي يشير إلى درجة شعور الفرد بالتهديد

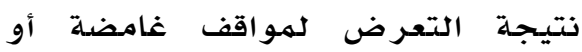

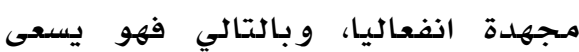


و متحمسين، بينهما تلدل الدرجة

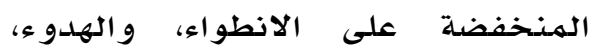
و التحفظ. وحددها كوستا و ماكرى ) وفى Costa \& McCrae)

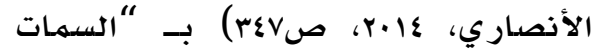

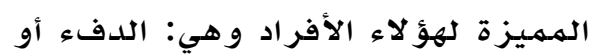

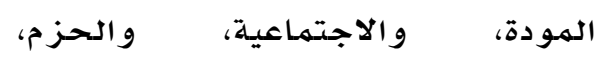

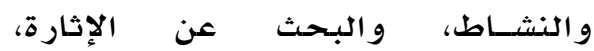
و الانفعالات والنثاط، والإيجابية". و والتعريف

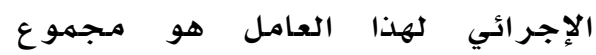
الدرجات التي يحصل عليها الفرد في

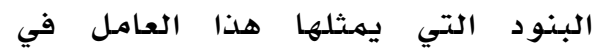
نهموذج العوامل الخمسـة للشخصية.

r. Openness to على الخبرات experience العقلي و الاهتمام بالثقافة، والدرجة والدة

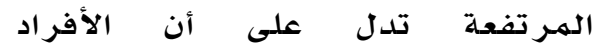

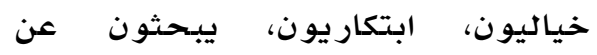

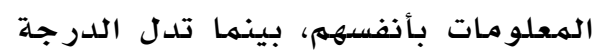
المنخفضة على أن الأفراد

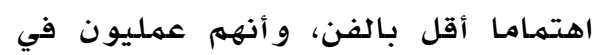

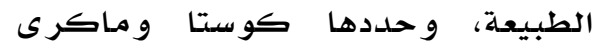
Costa \& McCrae)

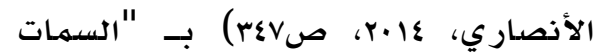

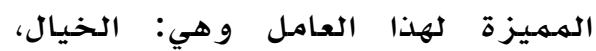

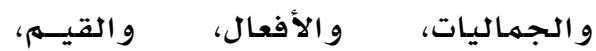

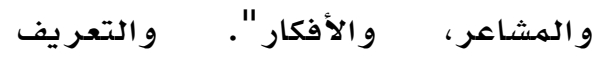

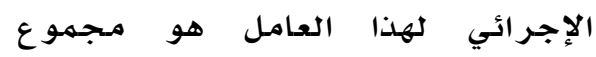

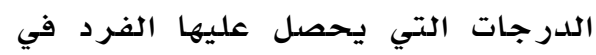

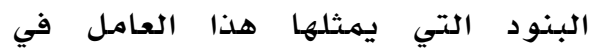
نموذذج العوامل الخمسية للشخصدية.

ع. القبول Agreeableness: ويعكس هذا هذا العامل كيفية التفاعل مع الآخرين،

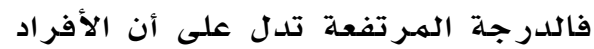

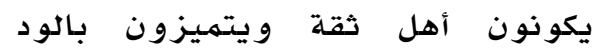

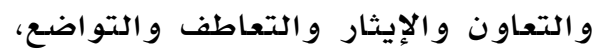

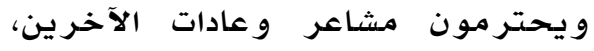

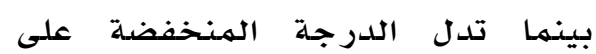

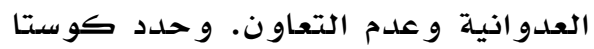

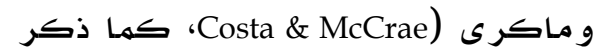

مجموع الدرجات التي يحصل عليها الفرد في البنود التي يمثلها هذا البعد البداب في مقياس مستح القيهم لقياس الأبعاد

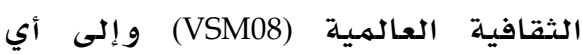
القطبين يميل الأفراد أكثر.

Five بموذج العوامل الخمسة للشخصية Factors Personality Model العوامل الخمسة للشخصية مـن أهم النهماذج

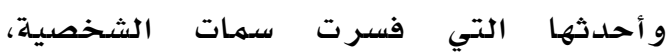

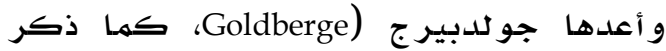

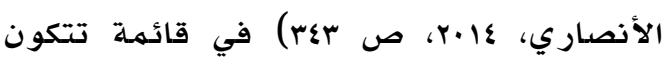

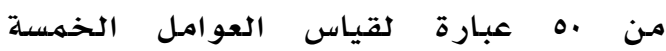
كلشخصية بواقع ·1 عبارات لكل عامل هي:

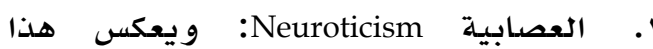
العامل الهيل إلى الأفكار و المشاعر

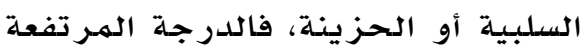
تدل على أن الأفر اد يتميزون بالهزيله هالعصابية

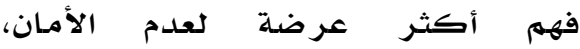

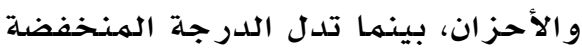

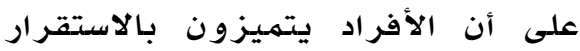
الانفعالي، وأكثر مـرونة، وأقل عرضيل

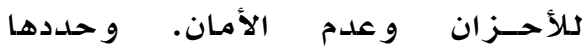
كوستا و مـاكرى (Costa \& McCrae)

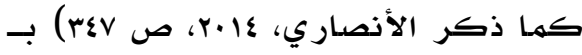

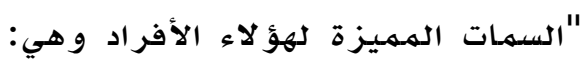
القلق، و عدائية الغضب، والاكتئئاب، والوعي بالنات، والاندفاعية، القابلية للانهزام أو عدم الو القدرة على تحلى تحمل

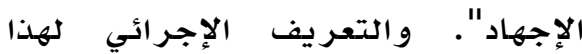

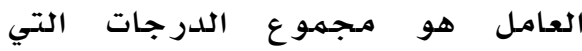

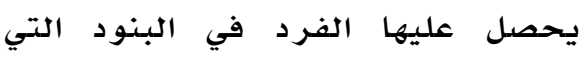
يمثلها هذا العامل في نهموذج العوامل الخمسسة للشخصية.

r. الانبساطية Extraversion: و ويعكس هذا العامل التفضيل للهمواقف الاجتماعية ولية

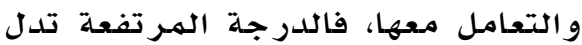

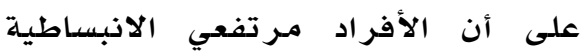

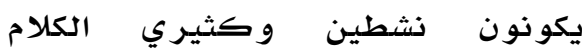
ويبحثون عن الجماعة ومسيطرين 


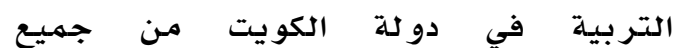

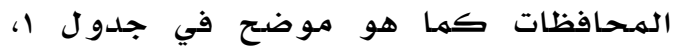

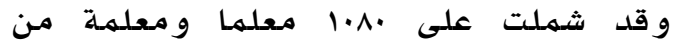

الجنسية الكويتية و المصرية بواقع •عه معلما

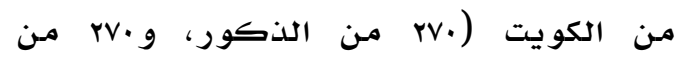

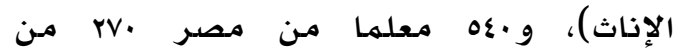

الذكور، و.rV مـ الإناث.

جدول 1

عدد المدارس الثانوية موزعة حسب المحافظة

\begin{tabular}{|c|c|c|c|c|c|c|}
\hline \multicolumn{7}{|c|}{ المحافظة } \\
\hline مبارك & الجهراء & الاحمدي & الفروانية & حولي & العاصمة & \\
\hline V & v & V & V & $\mathrm{v}$ & V & أولاد \\
\hline v & v & v & v & v & v & بنات \\
\hline
\end{tabular}

ادوات الدراسة

\section{مقياس مسح القيم لقياس الأبعاد الثقافية}

العالمية (Values Survey Module -VSM 08):

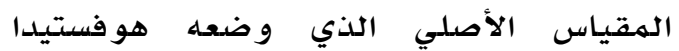

وتمت ترجمته لعدة لغنات (Roodt, 2003).

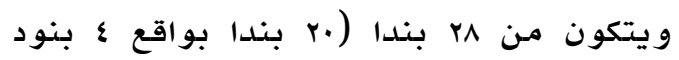

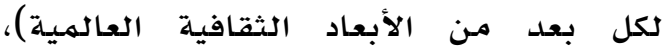

(و باقي البنود أسئلة شخصية)، و لقد صيغت بلاد

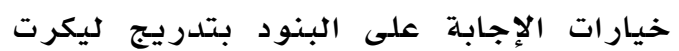

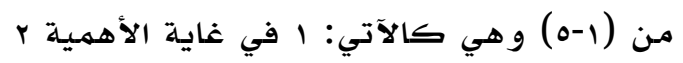

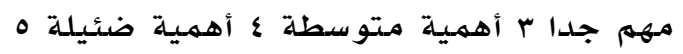

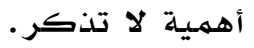

صدق الأداة وثباتها: تم حسـاب معامل ارتباط

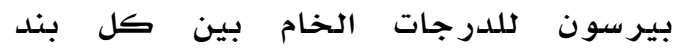

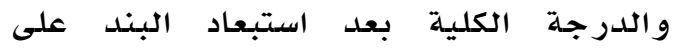

الهقياس الفرعي الواحد في مقياس الأبعاد

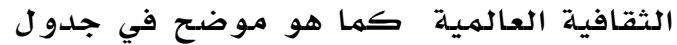

ويتضح من جدول r أن أغلب معاملات

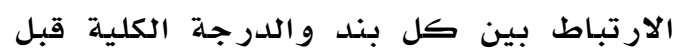

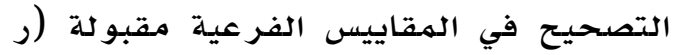

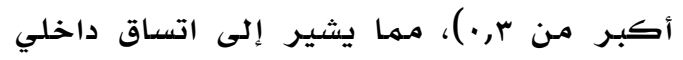

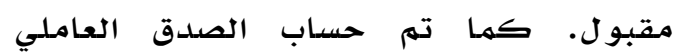
باستخدام التحليل العاملي بهدف التعرف

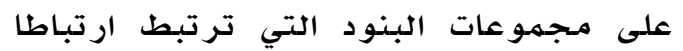

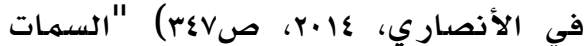

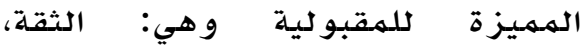

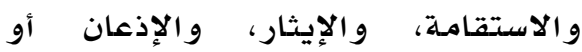

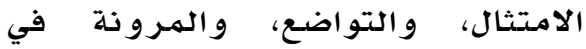

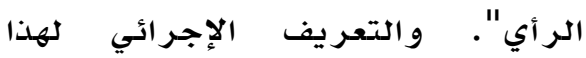

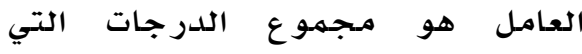
يحصل عليها الفرد في البنود التي يمثلها هذا العامل في نهموذج العوامل الخمسة للشخصية.

0. الإتقان Conscientiousness: و يعكس هذا العامل الهثثابرة والتنظيم لتحقيق

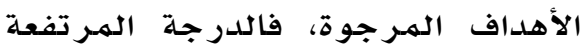

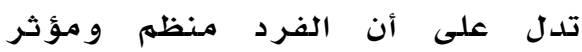
ويعتمد عليه ويؤدى واجباته باستمـرار

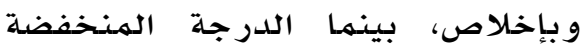
تدل على أن الفرد أقل حذرا وأقل

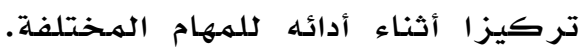

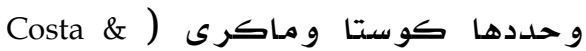

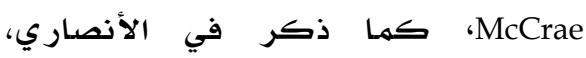
\&.r. لكلأفراد هي: الإتقان، الكفاءة، النظام،

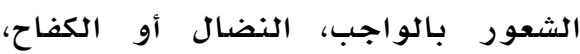
التأذي أو التروي، الانضباط أو الالتزام

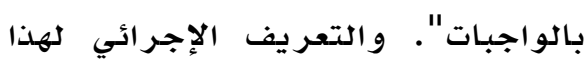

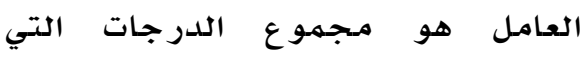
يحصل عليها الفرد في البنود التي

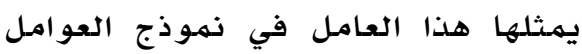

الخمسسة للشخصية.

الطريقة والإجر اءات

التصمييم

استخدم الباحثان في هذه الدراسلة الهنهج الوصفي الارتباطي المقارن لفحص العلانيان العانة

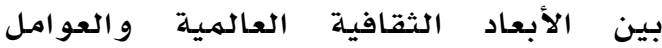

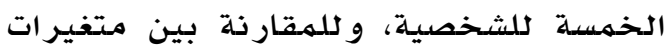
الدر اسـة وفقا لنوع و جنسية أفر اد العينة. العينة

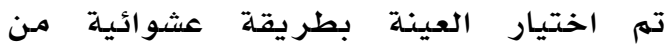
العاملين بالمدارس الثانوية التابعة لوزارة 
عوامل أحادية القطب حيث احتوى العامل

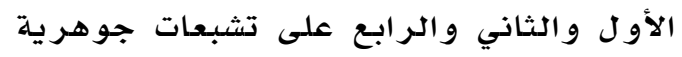

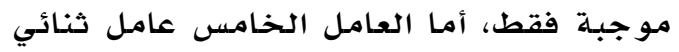

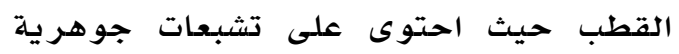

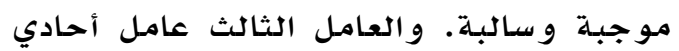
القطب فهو يحتوي على تشبعات سلبيية فقط.

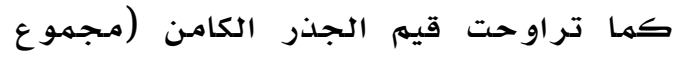

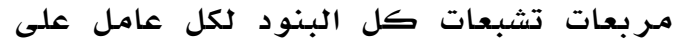

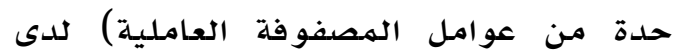

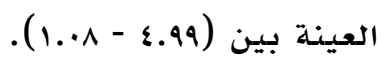

كبيرا بعضها مـع بعض. و لكنها ترتبط

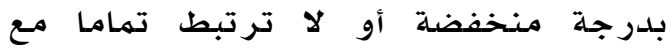

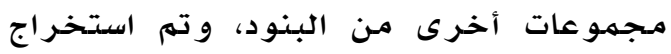

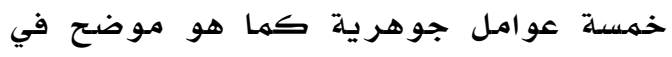

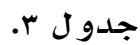

و يتضح من جلدول م أنه تم استخراج خمسة

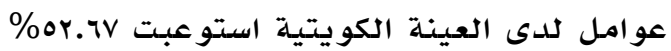
من التباين الكلي، فضلا أن بعض بنود مقياس النوليه

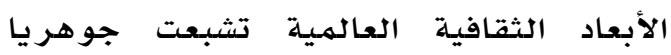

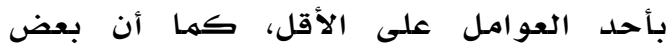

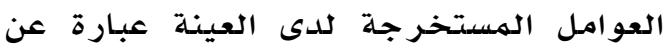
جلول

معاملات الارتباط بين كل بند والارجة الكلية قبل التصحيح على مقياس الأبعاد الثقافية العالمية

\begin{tabular}{|c|c|c|c|c|}
\hline 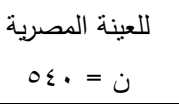 & 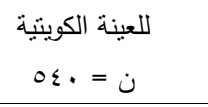 & 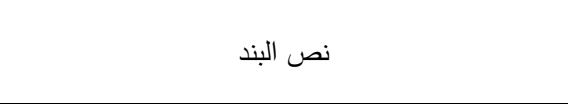 & رقم & الألعاد الثقافية \\
\hline, 700 & 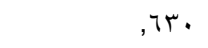 & الحصول على التقدير للأداء الجيد & r & \multirow{4}{*}{ مسافة القوة } \\
\hline, $7 \wedge 9$ &, $0 . \mathrm{V}$ & القيام بعمل ممتع & 1 & \\
\hline,$V \cdot r$ & . $\leqslant \pi t$ & التواضع & $1 \leq$ & \\
\hline,$\leqslant 19$ & .071 & هل أنت شخص سعيد؟ & iv & \\
\hline , rro &,$r \leqslant \wedge$ & توفر وقت كافي للحياة الثخصية والعائلية & 1 & \multirow{4}{*}{ الجمردية مقابل الفية } \\
\hline , rov &,$V \cdot r$ & توفر رئيس يمكناك احترامه & r & \\
\hline .071 & , $\mathrm{\wedge}$ & توفر وظيفة مضمونة وطويلة الأمد & $\varepsilon$ & \\
\hline , $70 \leqslant$ &,$v \leqslant r$ & المعيشة في منطقة مميزة & $\wedge$ & \\
\hline,$I T V$ &,$v \cdot 9$ & نوفر أناس مهذبين للعمل معهم & $\circ$ & \multirow{4}{*}{ 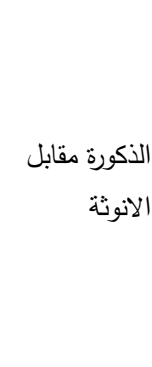 } \\
\hline $.01 \%$ &.$V Y \varepsilon$ & عملاك استشارتك من قبل رئيسك في القرارات التي تخص & v & \\
\hline .011 & דו7 & لثرائه لكنان لان تملك المال غالي الكافن ولديك رغبة شديدة & 10 & \\
\hline, $0 \wedge \wedge$ & , & هذه الايام؟ عام، كيف تصف الحالة الصحية الخاصة بك في & r. & \\
\hline,$\varepsilon \vee \Gamma$ & , $\varepsilon \vee \Gamma$ & 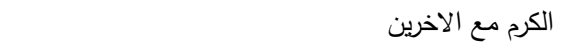 & ir & \multirow{4}{*}{ التيقن } \\
\hline r &, 0.7 & ما مدي احساسك بالقلق والتوتز & 17 & \\
\hline , Тะ. &, $0 \leqslant 0$ & هل هل شتصنيتك في أن الآخرين أو الظروف نفسا في البيت؟ عن عمل & 11 & \\
\hline 1806 & 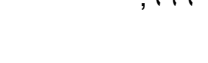 & شيء عزمت القيام به؟ & 19 & \\
\hline , thr & ב & توفر عمل يحترمه أقاربك وأصدقاؤك & 9 & التوجه طويل \\
\hline,$\wedge 10$ &,$\vee \vee q$ & توفر فرص للتزقية & 1. & 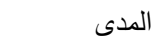 \\
\hline,$V \leqslant r$ & , $\vee \Upsilon \varepsilon$ & تخصيص وقت للمتعة والترفيه & 11 & مقابل التوجه \\
\hline תוT &,$v \cdot r$ & الاعتدال والتوسط & ir & قصير المدى \\
\hline
\end{tabular}




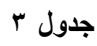

عوامل الرتبة الأولى المتعامدة المستخرجة من مقياس الأبعاد الثقافية العالمية

\begin{tabular}{|c|c|c|c|c|c|c|c|c|c|c|}
\hline \multicolumn{5}{|c|}{ العينة المصرية (ن=.عـم) } & \multicolumn{5}{|c|}{ العينة الكويتية (ن = •ـ؛ ) } & \multirow{2}{*}{ البند الن } \\
\hline 0 & $\varepsilon$ & r & $r$ & 1 & $\circ$ & $\varepsilon$ & r & r & 1 & \\
\hline$\ldots r l$ & .1 & $\therefore .00$ & $\cdot . \wedge r \wedge$ &. $.7 V$ & 政 & $\ldots T r$ & $\cdot 187$ & $\cdot .1 \cdot \varepsilon$ & $\cdots \vee \vee q$ & 1 \\
\hline$\therefore \wedge \vee 0$ & $\cdots 7$ &. .110 &. .07 & $\cdots \wedge$ & $\cdots+1$ &. .19 & $.7 r \wedge$ & $\ldots 70$ & $\because \wedge \wedge$ & r \\
\hline$\ldots 1 \mathrm{~V}$ & $.1 \leq 0$ & $\ldots r q$ &..$r v$ &. $.0 \mathrm{~V}$ &. .19 &. $.1 T V$ & $\cdot r \cdot O$ & $\cdots \wedge$ & $\therefore \leqslant 09$ & r \\
\hline$\because 1$ & $\ldots 9$ & $\ldots r$ & ..or & $.79 \pi$ &. $.0 \mathrm{~V}$ & $.1 T_{7}$ &. $.10 r$ & $\ldots$ ro & $.7 r \leq$ & $\varepsilon$ \\
\hline$\ldots .07$ & $\therefore$ roo & $\ldots .01$ & $\because v r \Lambda$ & .1 .0 & $\cdots \wedge 1$ & $\ldots r \leq$ & .194 & דיז.. & $.7 \vee \wedge$ & 0 \\
\hline$\ldots 91$ & $\ldots r \Lambda$ & $\ldots .00$ & ..r人 & $\because v \cdot q$ & $\cdots \times 1$ &.$r .0$ & $\because$ roN & $\ldots .01$ & $\cdot . \wedge .0$ & 7 \\
\hline .10 & $\ldots 19$ & דrar & $\because \vee \vee 91$ &. .101 & ..rr &. $.1 \mathrm{r}$ & $\cdots \wedge \varepsilon$ & $\ldots \leqslant \wedge$ &. .709 & v \\
\hline .1 ro & $\cdots 9$ & $\ldots+$ & $\cdots \leqslant 1$ & 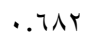 &..$+1 r$ & .ror & $\cdot .1 \leq r$ & דr... & $.7 \wedge \varepsilon$ & $\wedge$ \\
\hline. .104 & $\ldots \vee \wedge$ &. $.1 \cdot r$ &. $.7 V$ & $\therefore \vee 09$ & ...Tr & $\ldots V Y$ &. $.09 r$ & $\ldots \varepsilon$ & $\because 1 r 9$ & 9 \\
\hline ..ro & $. .1 \leq 1$ & ...r4 & $\cdots 1 \leq$ & 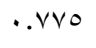 & $\cdots 70$ & $\because r \cdot q$ & . .TYV & $\ldots$ vo & .rIV & 1. \\
\hline.$\| 1$ & $\ldots 94$ & $\ldots 0 \leq$ & $\because \cdot V r$ & $\because V \backslash r$ & $\ldots+r \Lambda$ & $\cdots \cdots$ &.$T \vee \wedge$ & $\ldots r V$ & $\because r$ & 11 \\
\hline$. .1 \leq \varepsilon$ & . & ת4ד & $\ldots r$ & $\because$ r^q & -.1Y7 & זדז.י & .7199 & $\ldots+r q$ & $\ldots 0$ & ir \\
\hline$\ldots 19$ &.$V Y V$ & $\ldots r$ & .119 & .rrq & .IrT &. tor & .19 & $\ldots 17$ & .1 .7 & ir \\
\hline$\ldots 0$ &.$r 00$ & $\ldots \times 1$ & $\cdots 99$ & . .0YT & .711 & $\ldots \times 4$ & $\cdot r \cdot V$ & $\cdots \wedge \varepsilon$ & $. . r \leq$ & $1 \leqslant$ \\
\hline$\ldots 7 \leq$ & ת474 & .110 & $\ldots+1 \mathrm{~V}$ & .007 & דצדי. & .. & $\cdots V V$ & $\ldots V r$ & $\because \leqslant \leqslant 1$ & 10 \\
\hline .rq. & $.11 \mathrm{~V}$ &.$\varepsilon \Sigma V T$ & $\because r \leq$. & $\ldots .0 \mathrm{~V}$ & .794 &.$Y 99$ &..$\cdot r$ & $\ldots \leq \varepsilon$ &. .111 & 17 \\
\hline דזי.. & $\cdots \leq \leqslant$ & $\cdot .1 .0$ & $\because .97$ & $\cdots \wedge$ & ..ro & $\because r \leq r$ & דואו. & ד.7人t & $\cdots \vee \wedge$ & iv \\
\hline$\ldots \wedge r$ & $.0 Y \wedge$ & rr... & $.0 \leqslant r$ & . TVY & $. M+1$ &.$r \backslash 1$ & $\cdot . r \cdot T$ & .. & $\cdot r \cdot \lambda$ & 11 \\
\hline$\ldots 99$ & $. r \mid r$ & $\because .1 \leq 9$ & .701 & $\cdots \wedge \leq$ & & .007 & $\cdots 9$ & ד47ד. & $\cdots \times 1$ & 19 \\
\hline$\ldots+r$ & .1 & .000 & $\cdot . \wedge r \wedge$ & $\ldots 7 V$ &..$M T V$ & $\ldots$ Tr & .184 & $\cdots 1 \cdot \varepsilon$ & $\cdots \vee \vee q$ & $r$. \\
\hline $1.1 . r$ & $1 . M 1 Y$ & $1 . \Sigma r V$ & r.NIT & $\varepsilon . \wedge 1$ & $1 . . v V$ & 1.171 & $1 . \Sigma T r$ & $1 . \wedge \leq 7$ & $\varepsilon .9 \wedge \mathrm{V}$ & الجذر الكامن \\
\hline $0.01 \mathrm{r}$ & 7.009 & V.lAr & $1 \leq . .7$ & $r \varepsilon \ldots .0$ & 0.rNT & $0 . \Lambda \cdot r$ & V.MIT & Q.rTr & $r \varepsilon .9 r$ & تباين العامل \\
\hline & & OV.rv & & & & & OY.T7E & & & التباين الكلي \\
\hline
\end{tabular}

ويعرض جلدول \& معاملات الشيوع لبنود

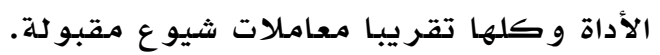
كما تم التحقق من ثبات الأداة باستخدام

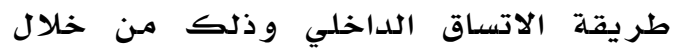
معامـلات ألفا من وضع كرونباخ بعد احد تطبيق

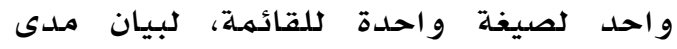

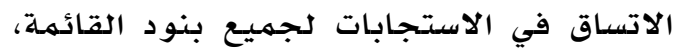

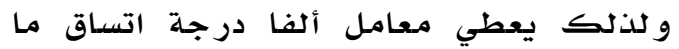

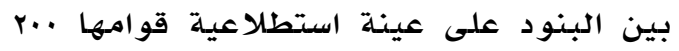
فرد مـن المعلمين الكويتيين و والمصرين ئين

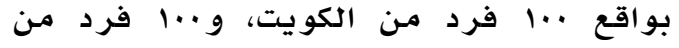

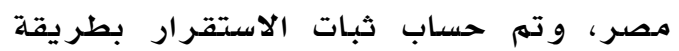
إعادة التطبيق بعد أسبوع على عدد العينـة

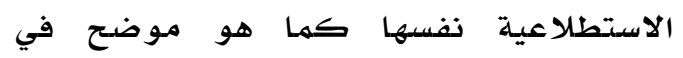
جدو ل 0.
كذلك تم استخراج خمسة عوامل لدى لدى

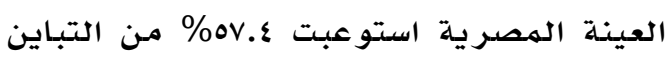
الكلي، فضلا أن بعض بنود مقياس الأبعاد

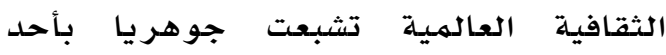

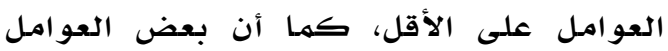

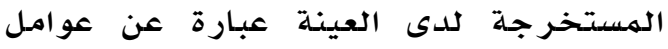
أحادية القطب حيث احتوى العامل الأول

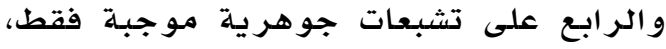

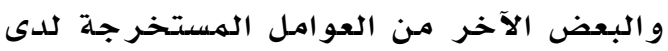

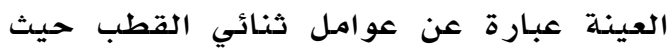

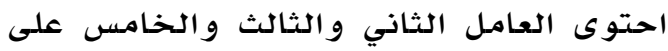

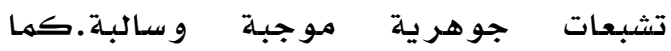

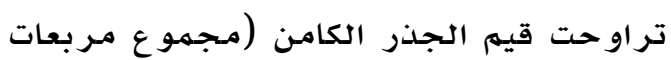

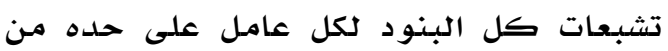

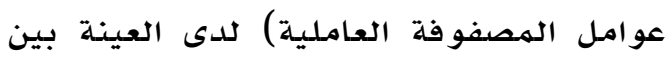
. (1.1 - ع.1) 
الشخصية (عبدالخالق، ....r)، و من هنا فإن

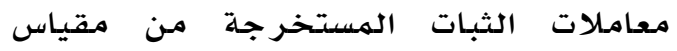
الأبعاد الثقافية العالهية تعتبر مرتفعة لأنها تراوحت بين (v.••-ه.••).

Five ب - نموذج العوامل الخمسة للشخصية Factors Personality Model Goldberg)

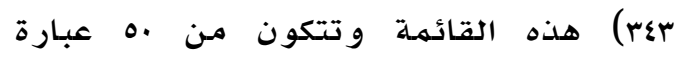

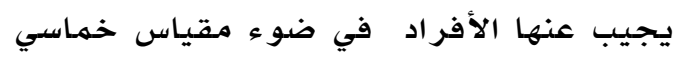
التدريج لقياس العوامل الخمسية للشخصية

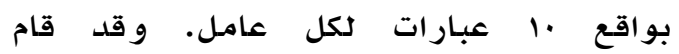

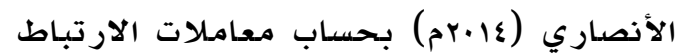

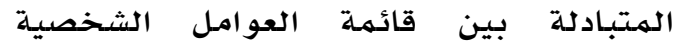

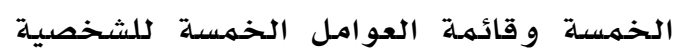

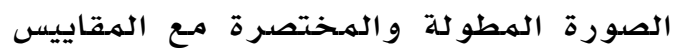

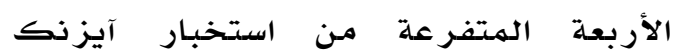
على (Eysenck Personality Questionnaire-EPQ) عينة مستقلة قوامها ... طالب وطالبة من

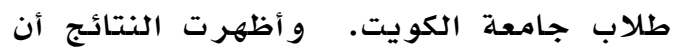
مقياس الانبساط يرتبط أكثر بالإتقان

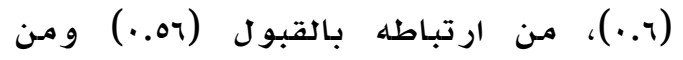

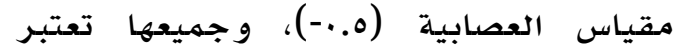
ارتباطات متوسطة، في حين يرتبط مقياس

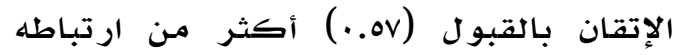

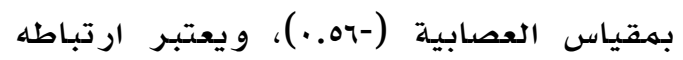

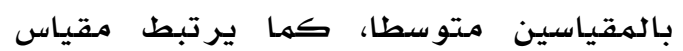

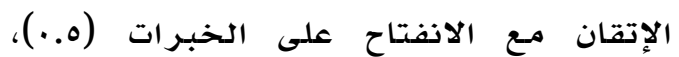

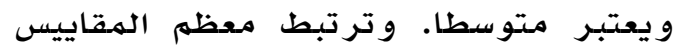

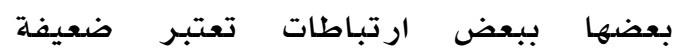

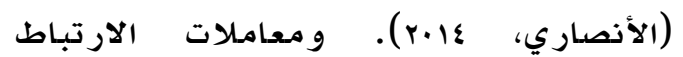

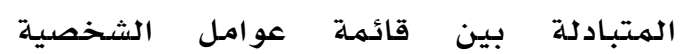

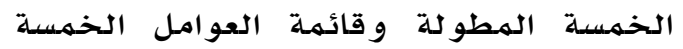
للشخصية المختصرة جوهرية عند مستوى الهوله (1...) و جمعيها ارتباطات ضعيفة (الأنصاري، .$(r \cdot 1 \varepsilon$

\section{إجر اءات الدراسة}

تم الحصول على إذن خطي من جامعة

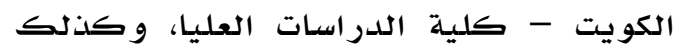

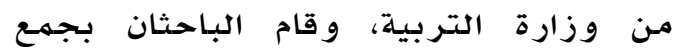

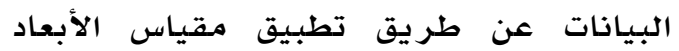

جدول ؛ معاملات الشيوع جلاك

\begin{tabular}{|c|c|c|}
\hline للعينة المصرية & للعينة الكويتية & رقم البند \\
\hline$\because v \cdot 0$ & $.10 \leqslant$ & 1 \\
\hline$\because \vee \vee \varepsilon$ & .001 & r \\
\hline..$r q$ & דצח. & $r$ \\
\hline דrory & . 041 & $\varepsilon$ \\
\hline .7 .7 & $.0 \mathrm{VI}$ & 0 \\
\hline $.0 T \leq$ & .771 & 7 \\
\hline $.7 N 1$ & TH. & V \\
\hline.$\quad \varepsilon V \Gamma$ & .000 & $\wedge$ \\
\hline $.01 \mathrm{r}$ & $\therefore \varepsilon \cdot \varepsilon$ & 9 \\
\hline .071 & .TYV & 1. \\
\hline .011 & $.09 \pi$ & 11 \\
\hline $.01 r$ &. $.0 \mathrm{NV}$ & Ir \\
\hline .799 & $.0 Y \wedge$ & Tr \\
\hline$\cdots \leqslant 99$ & $\cdot . \leqslant 7 \wedge$ & $1 \varepsilon$ \\
\hline .089 & $.7 \leq 9$ & 10 \\
\hline .0 .1 & .071 & 17 \\
\hline$. T \leq \varepsilon$ &. $.0 \mathrm{VT}$ & IV \\
\hline $.71 \wedge$ & $\cdot \varepsilon q 9 \wedge$ & 11 \\
\hline$\because \leqslant q \vee$ & .049 & 19 \\
\hline$\because v .0$ & $.10 \leqslant$ & $r$. \\
\hline
\end{tabular}

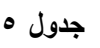

معاملات الثبات للأبعاد الثقافية العالمية

\begin{tabular}{|c|c|c|c|c|}
\hline \multirow{2}{*}{\multicolumn{2}{|c|}{ 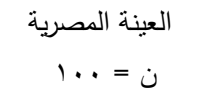 }} & \multicolumn{2}{|c|}{ العينة الكويتية } & \multirow{3}{*}{ الأبعاد الثقافية } \\
\hline & & & & \\
\hline النطبيق & ألفا & التطبيق & ألفا & \\
\hline. .9 &..$v$ &..$v$ &.$V V$ & مسافة القوة \\
\hline$\therefore$ Vo & .174 & $\because v$ & $\because v$ & مقابل الجمعية \\
\hline..$\wedge \varepsilon$ &.$\Delta r$ & . . &.$\wedge T$ & الذكورة \\
\hline . .AT &.$\vee v \wedge$ &.$V T$ &.$V V$ & تجنب عدم \\
\hline.$v r$ &.$V Y$ & $\therefore V$ & $\because v 0$ & التوجه طويل \\
\hline
\end{tabular}

وتشير النتائج المستخرجة من جدو ل ه إلى ارتفاع معاملات ثبات ألفا وإعادة التطبيق في التهني العينـة الاستطلاعية للمعلمين الكويتيين و المصريين، ومن ثم تعد معامـلات الثبات

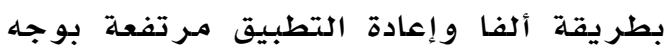
عام، حيث يعد معامل الثبات الذي يساوي أو أو

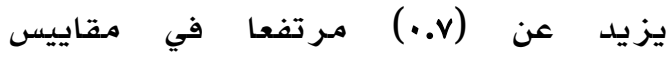


ويوضتح جدول 1 وجود فروق دالة إحصائيا

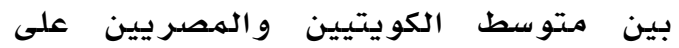
مقياس مستح القيم لقياس الأبعاد الثقافية

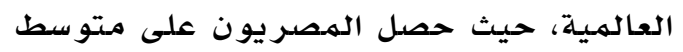

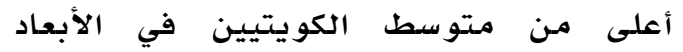

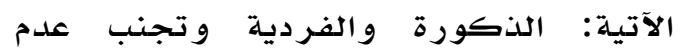
التيقن. في حين حصل الكويتيون على ألى متوسط أعلى من متوسط الهصرئين في بعدي

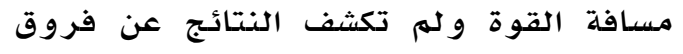
ذات دلالة إحصائية بين الكويتيين والمصريين في بعد التوجه طويل المدلى.

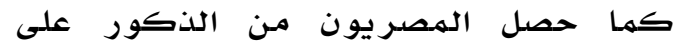

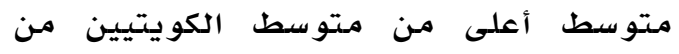

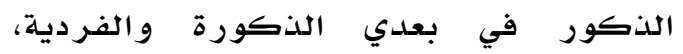

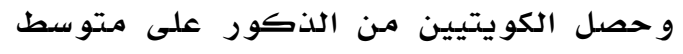

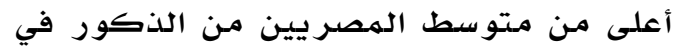

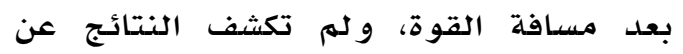
فروق ذات دلالة إحصائية بين الكويتيين

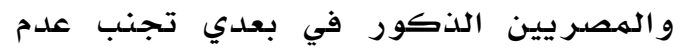
التيقن و التوجه طويل الهمدى.

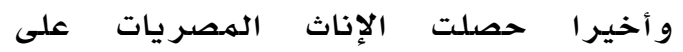
متوسط أعلى من متوسط الإناث الكويتيات

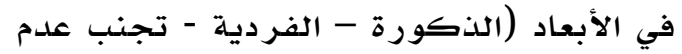
التيقن)، و أما الإناث الكويتيات فقد الاد حصلن على متوسط أعلى من مترسط الإنات الإناث

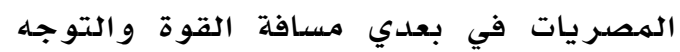

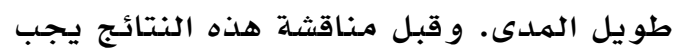
أن نشير إلى أن هذه الدراسة أجريت على على ملى أنساهل

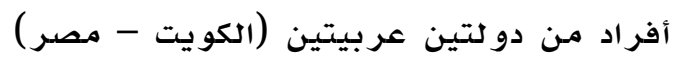
و لا يوجد ايلة دراسات تناولت الأبعاد الثقافية دولية العالهية بين دولة عربية وأخرى أجنبية

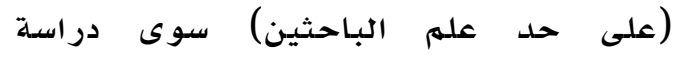

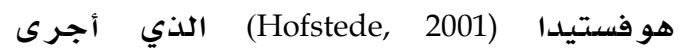

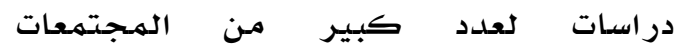
و الثقافات، كانت من بينها دراسة عن العالم

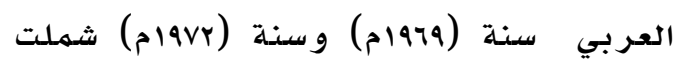
مصر و والعراق و والكويت و ولبنان و وليبيا

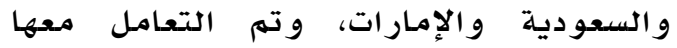

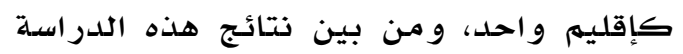

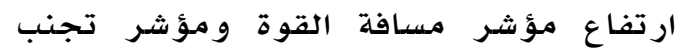

الثقافية العالهية وقائمة العوامل الخهسة

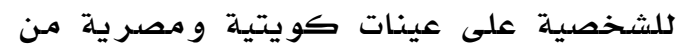
معلهي وزارة التربية، وتمت عملية التطبيق

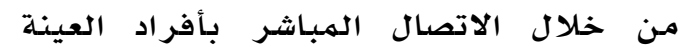

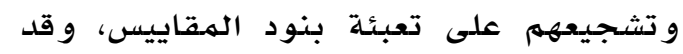

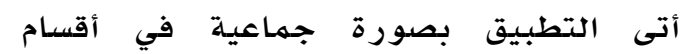

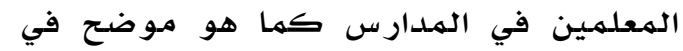

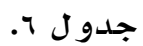

الأساليب الإحصائية: تم إدخال البيانات في

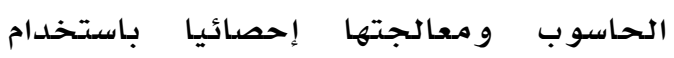

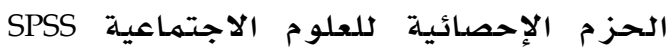
لحسـاب ما يلي:

معامـلات الارتباط لتقدير الثبات والصدق لمقياس مستح القيه لقياس

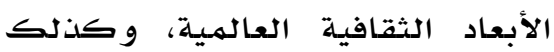

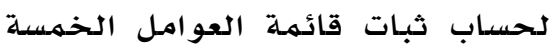
للشخصية، ولحساب العلاقة بين

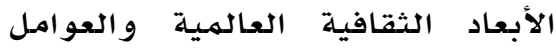
الخمسسة للشخصية.

التحليل العاستكشافي لمتغير ات الدر اسـة.

اختبار "ت" للمقارنة بين مجمهوعات

الدراسة في الهتغير ات الشخصيسار.

\section{نتائج الدراسة ومناقشتها}

الفرض الأول: توجد فروق دالة إحصائيا في الأبعاد القافية العالمية في ضوفية ضوفئ متغيريري الجنس النوع و الجنسية. و للتحقق من صححة الندية الفرض قام الباحثان باختبار (t-test) لإيجاد الفروق بين عينة المعلمين الكويتيين قوامها

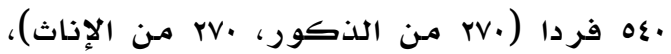

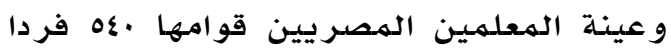

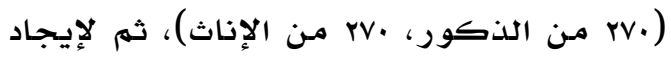
الفروق بين عينة الذكور الكويتيين التي قوامها ·rV فردا، و الذكور المصري

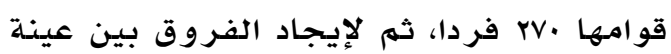

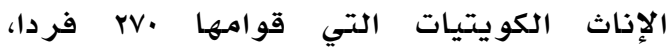

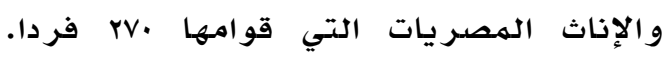
كما هو موضح في جدو ل 7. 
المتوقع و عدم قبو لها بالتغيير أو المخاطرة،

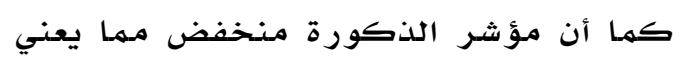
تقاربا بين قيهم الرجال و النساء في هذونه

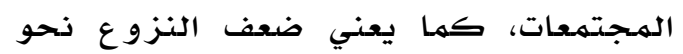

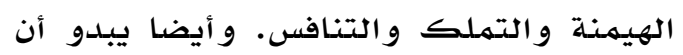

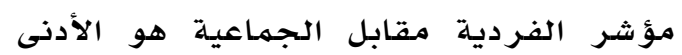

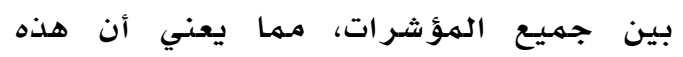

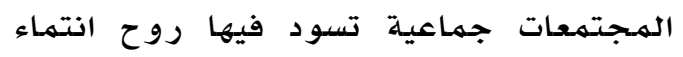
الفرد للمجتهمع وو لائه له اله
عدم التيقن، ويستنتج هوفستيدا من ذلك أن هذه المـجتمعات لا تسهمح بانتقال مواطنيها إلى الأعلى، و أن الفوارق في السلطة والثروة

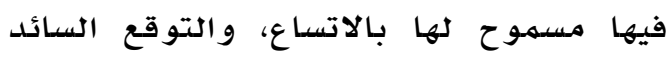

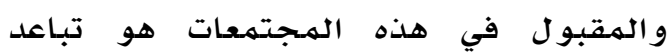

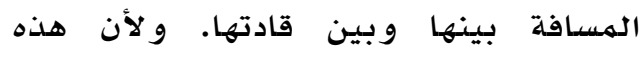

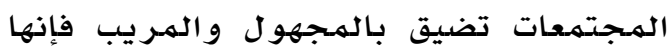

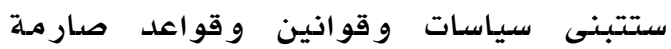
لضمان عدم مواجهة المجهول أو حلدوث غير

جدول 7

الفروق بين الكويتيين والمصريين على مقياس مسح القيم لقياس الأبعاد الثقافية العالمية

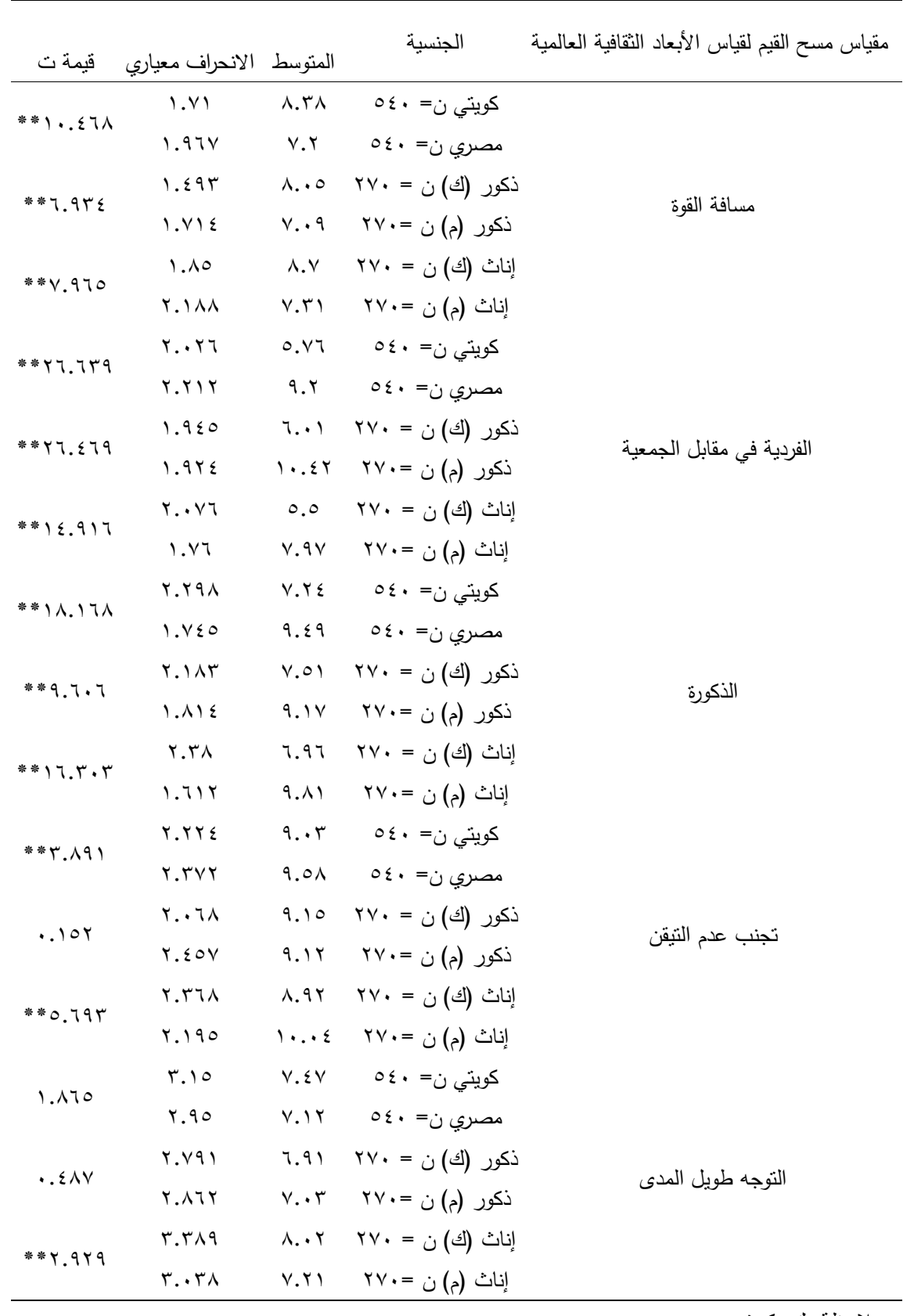


الكويتيين و المصريين، أما الدراسة الحالية

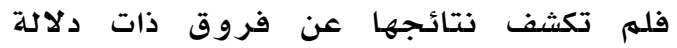

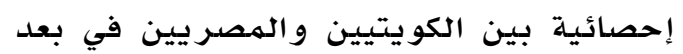

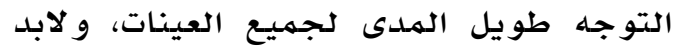

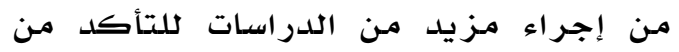
هذه النتائج.

الفرض الثاني: متوسط الأبعاد الثقافية

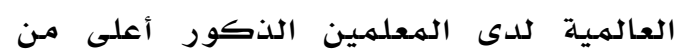

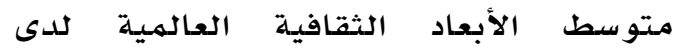

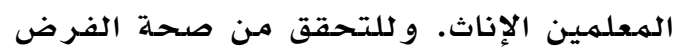

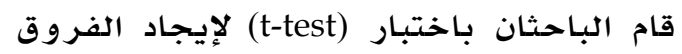
بين عينة الذكور وعينة الإناث، ثم لإيجاد الفروق بين عينة الذكور الكويتيين والإناث الكويتيات، ثم لإيجاد الفروق بئه الهروف عينـة الإناث

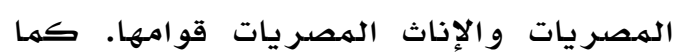

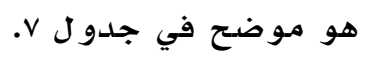

ويوضسح جدول V وجود فروق جوهرية بين

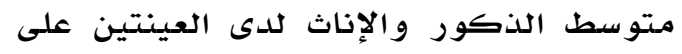
مقياس مستح القيهم لقياس الأبعاد الثقافية

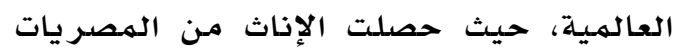

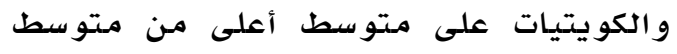

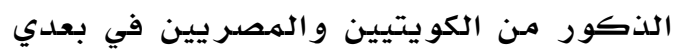
مسافة القوة والتوجهه طويل المدىى. و تتفق

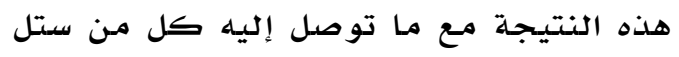

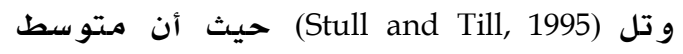

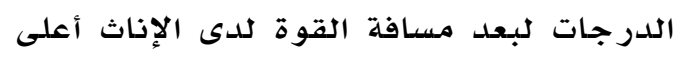

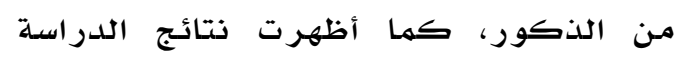
الحالية أن الإناث (الكويتيات و المصريات المهريات)

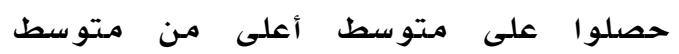

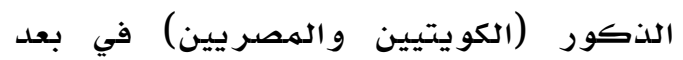
تجنب عدم التيقن، ولا توجد أية دراسات

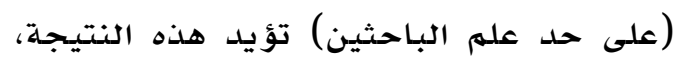

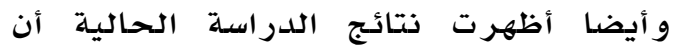

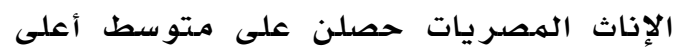

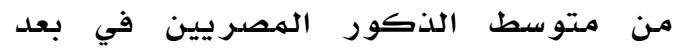
الذكورة. و أيضا كشفت الدراسـة الحالية أن الن الندين الذكور الكويتيين حصلوا على متوسط أعلى

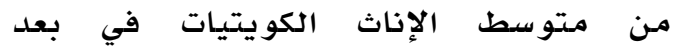

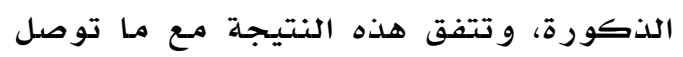

(Hofstede, 1991). و.بالرجوع إلى الإطار

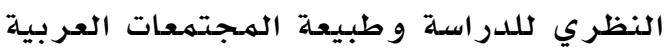

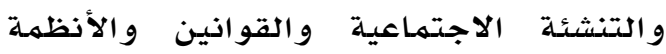

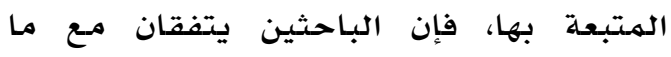
توصل إليه هوفستيدا في دراسته عن العالم العربي.

وبحسب مـاء جاء في دراسات هوفتيدا .(Hofstede, Hofstede, \& Minkov, 2010) فدرجات الأبعاد الثقافية بين الكويت و مصر كانت كالآتي: في بعد مسافة القوة كانت

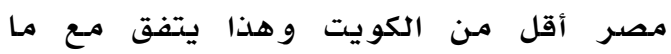
توصل إليه الباحثان الحاليان لجميع العينات

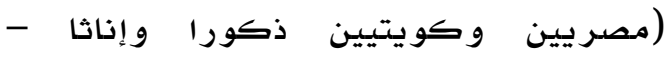

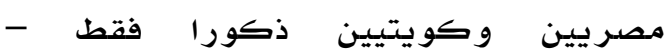
مصريين وكويتيين إناثا فقط ). موتينين وتساوت

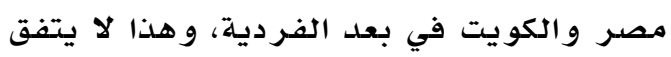

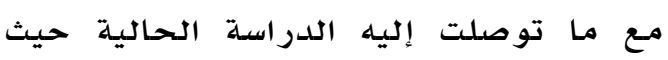

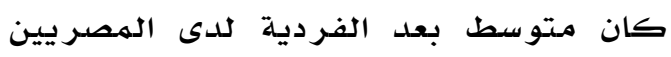

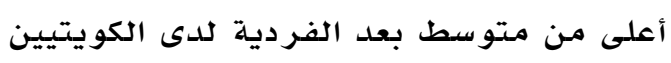

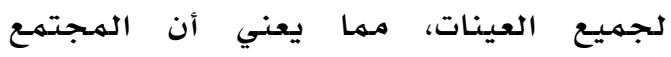

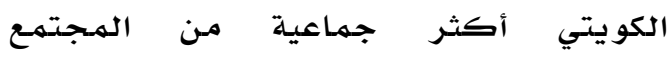

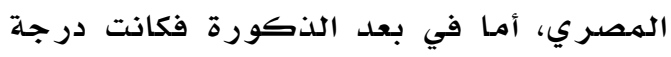

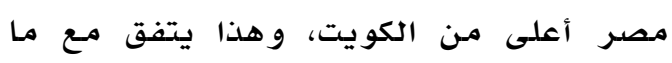

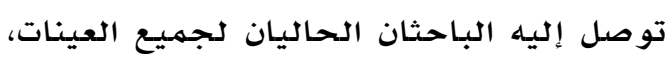

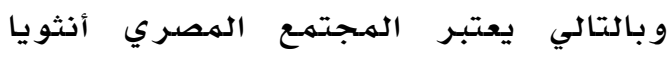
نسبيا أكثر من المـجتمـع الكويتي. أما بعد الهدئ

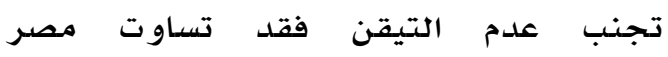

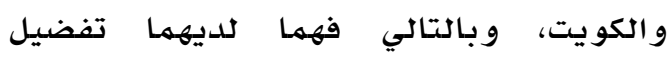
متساو إلى تجنب عدم التيقن، ولم تلتفق

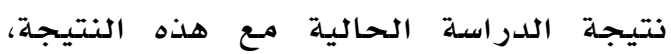
حيث كان متوسط بعد تجنب عدم التيقن لدى المصريين أعلى منسه لدى الكويتيين،

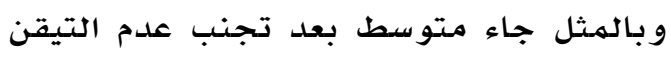

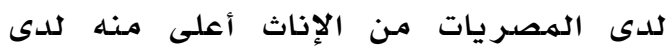

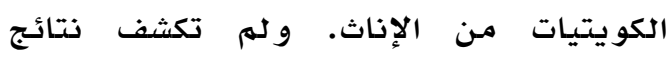

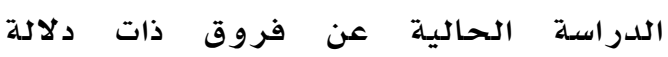
إحصائية بين الكويتيين و الهصريهين الذكور

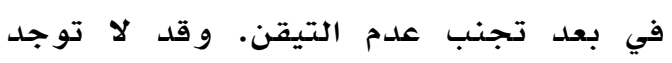

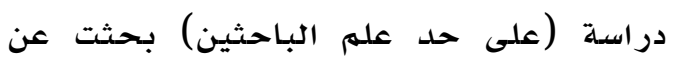

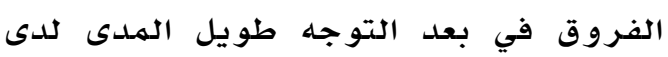




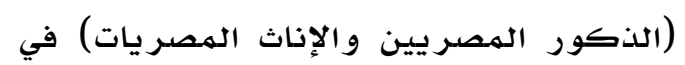

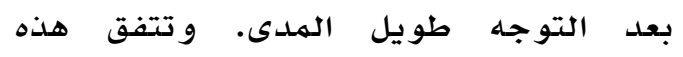
النتيجة مع ما توصل إليه كل من فئ فانس النس

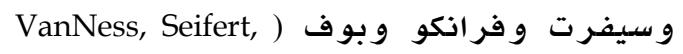

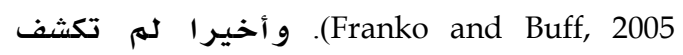

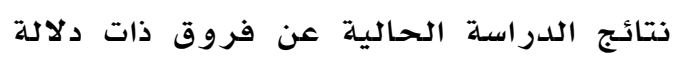

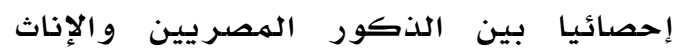

المصريات في بعد مسافة القوة. والمتتبع في الحمانيان

نتائج الدر اسات السابقة،
إليه كل من فانس وسيفرت و فرانكو وبوف (VanNess, Seifert, Franko and Buff, 2005) أن متوسط الدرجات لبعد الذكورة لدى

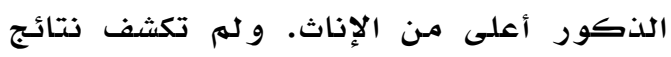
الدراسة الحالية عن فروق ذات دلالدة إحصائيا بين الذكور والإناث في بعدي الفردية

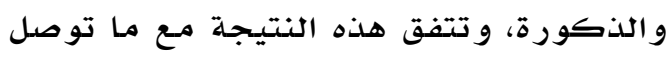
إليه كل من ستل و تل (Stull and Till, 1995)،

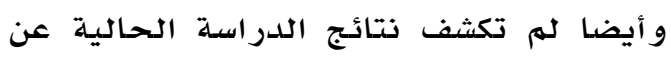
فروق ذات دلالة إحصائية بين كل من الدالية الحالية

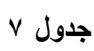

الفروق بين الأكور والإناث على مقياس مسح القيم لقياس الأبعاد الثقافية العالمية

\begin{tabular}{|c|c|c|c|c|}
\hline ق قيمة ت & انحراف معياري & المتوسط & النوع & مقياس الأبعاد الثقافية العالمية \\
\hline \multirow{2}{*}{$* *$ * r.ソ. } & $1.7 \mathrm{V4}$ & v.ov & ذكور ن= . §。 & \multirow{6}{*}{ مسافة القوة } \\
\hline & r.I乏 & A.. & إناث ن= • ؟ & \\
\hline \multirow{2}{*}{$* * \varepsilon . \leqslant \wedge$} & $1 . \Sigma 94$ & $1 . .0$ & ذكور (ك) ن= • & \\
\hline & 1.10 & A.V & إناث (ك) ن = rv. & \\
\hline \multirow{2}{*}{1.79} & $1 . v 1 \varepsilon$ & $v . .9$ & ذكور (م) ن = • & \\
\hline & r.1M & V.r. & إناث (ح) ن = rv. & \\
\hline \multirow{2}{*}{$* *$ *. $_{0}$} & r.9rr & A.rr & ذكور ن= • ؟ & \multirow{6}{*}{ 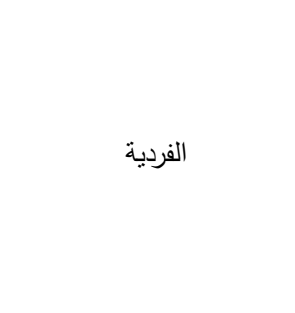 } \\
\hline & T.YAT & T.V & إناث ن= • ؟ & \\
\hline \multirow{2}{*}{$* * r .90$} & $1.9 \leqslant 0$ & $9 . .1$ & ذكور (ك) ن= • rv & \\
\hline & r..VY & 0.0 & إناث (ك) ن = rV & \\
\hline \multirow{2}{*}{$* * 10 . \varepsilon r$} & $1.9 r \varepsilon$ & $1 \ldots \varepsilon r$ & ذكور (م) ن = • & \\
\hline & 1.17 & v.9v & إناث (م) ن = & \\
\hline \multirow{2}{*}{.. $\mathrm{TV}$} & r.IV & $\lambda . r \varepsilon$ & ذكور ن= • ؛ـ & \multirow{6}{*}{ 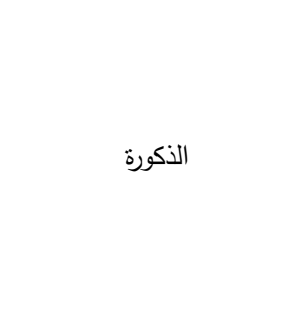 } \\
\hline & r.乏Ar & A.ra & إناث ن= • ؛ & \\
\hline \multirow{2}{*}{ **Y.YV } & r.lAT & v.01 & ذكور (ك) ن= •rv & \\
\hline & T.ru & 7.97 & إناث (ك) ن = rv. & \\
\hline \multirow{2}{*}{$* * \varepsilon . \sqcap 9$} & $1 . \wedge 1 \varepsilon$ & $9.1 \mathrm{~V}$ & ذكور (م) ن = • & \\
\hline & $1.71 r$ & 9.11 & إناث (a) ن = & \\
\hline \multirow{2}{*}{$* * Y . \leqslant 0$} & r.r.9 & $9.1 \%$ & ذكور ن= • ؟ـ & \multirow{6}{*}{ تجنب عدم التيقن } \\
\hline & $r . r \leqslant \Lambda$ & १.६^ & إناث ن= • ؛ & \\
\hline \multirow{2}{*}{$1 . r$} & r... & 9.10 & ذكور (ك) ن= •rv & \\
\hline & r.r.M & $0.9 r$ & إناث (ك) ن = rV. & \\
\hline \multirow{2}{*}{$* * \xi .01$} & r. ¿०V & 9.14 & ذكور (م) ن = . & \\
\hline & $r .190$ & $1 \ldots \varepsilon$ & إناث (م) ن = & \\
\hline \multirow{2}{*}{$* * r . \leqslant 0$} & r.ArE & $7.9 \mathrm{~V}$ & ذكور ن= . عه & \multirow{6}{*}{ التوجه طويل الددى } \\
\hline & $r . r \leq 1$ & V.T & إناث ن= • ؛ & \\
\hline \multirow{2}{*}{ **ะ. } & r.va) & 7.91 & ذكور (ك) ن= = rV & \\
\hline & $r . r \wedge 9$ & A..r & إناث (ك) ن = rV & \\
\hline \multirow{2}{*}{. .79} & T.NTY & $v . . r$ & ذكور (م) ن = . & \\
\hline & $r . . r \Lambda$ & Y.r. & إناث (م) ن = rv. & \\
\hline
\end{tabular}

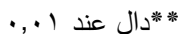


دلادة إحصائيا بين بعد الفردية و وعامل

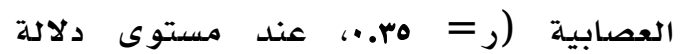

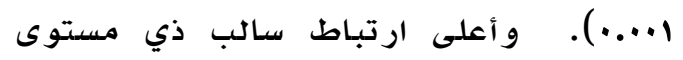

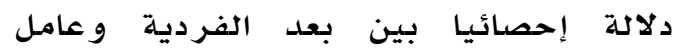

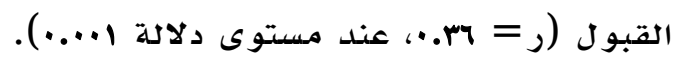

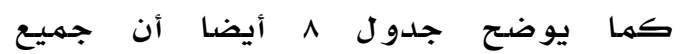

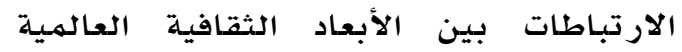

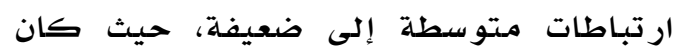

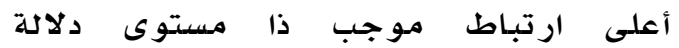

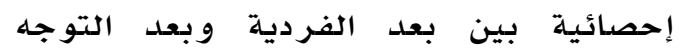

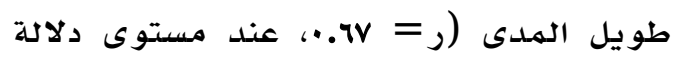
.....)

وبالرجوع إلى الإطار النظري للدراسلة، فقد افترض الباحثان في الفرض الثر الثالث و وجود علاقة ارتباطيه موجبـة ذات دلادئة إحصيائيا

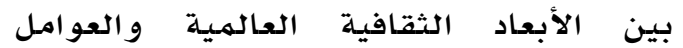
الخمسـة للشخصية لدى المعلمين الكويتيين

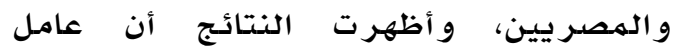

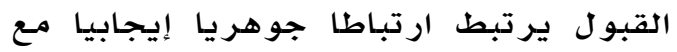

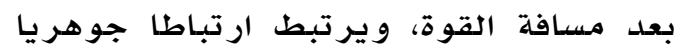
سلبيا مـع بعد الفردية وبعد الذكورة وبعد وبعد تجنب عدم التيقن. كما تشير نتائج الدراسلة

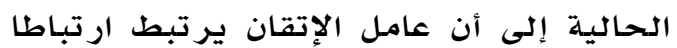
موجبا جوهر يا مـع بعدي الفردية و الذكورة،

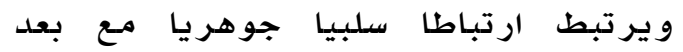
مسافة القوة وبعد تجنب عدم التيقن وبعد

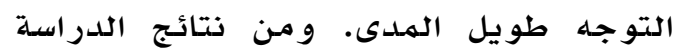
الحالية عدم وجود طودية علاقة بين الانبساطية و مسافة القوة، وذلك يتعارض مـع نتائج دراسـة ألك و ماكري ( Allik and McCrae, 2004) التي تؤكد أن عامل الانبساطية يرتبط وريط

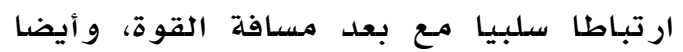
تؤكد الدراسـة الحالية أن عامل الانبساطية

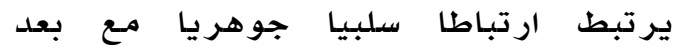
الفردية وبعد الذكورة وبعد تجنب عدم جهد

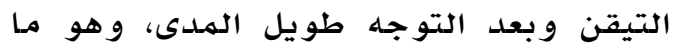

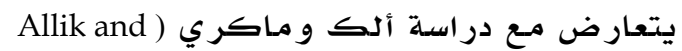
.(McCrae, 2004
التي تناو لت الفروق بين الذكور والإناث في الأبعاد الثقافية العالمية لا يستطيع الخروف بنتيجة حاسمة نظرا لتعارض ل نتائجها.

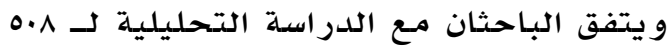

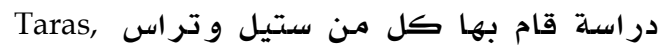

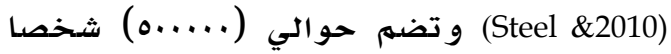
من 7و بلدا، حيث راجعت دراسات عديدة لمعر فة ما إذا كان هناك فروق بلئ بين الذاتكور

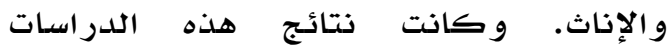
متفاوتة بجميع الأبعاد، حيث أظهرت بعض

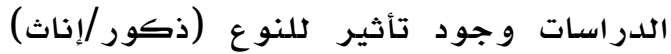

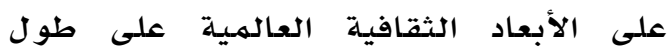

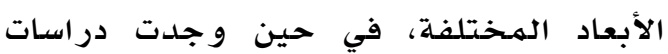

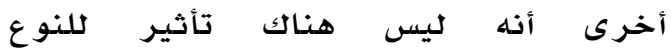

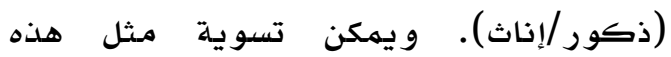

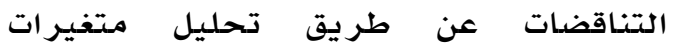
وسيطة: كالوضع الاجتماعي و والاقتصادي

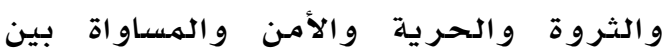

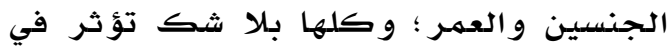

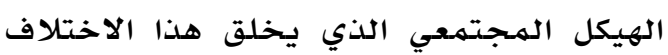
بين الجنسين. الفرض الثالث: توجد علاقة موجبة ذ ذات دلادة إحصائيا بين الأبعاد الثقافية العالمية

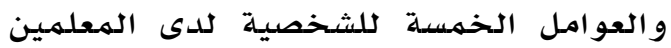

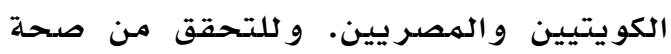
الفرض قام الباحثان بإيجاد معاملات بير سون

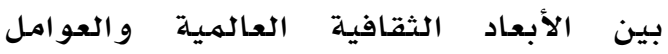

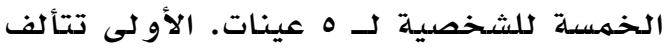
من الكويتيين و المصر يين قوامها ·می+1 فردا،

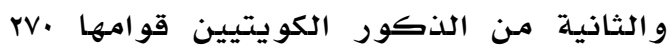

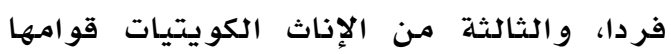

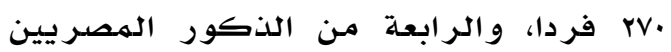

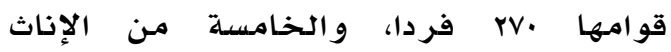

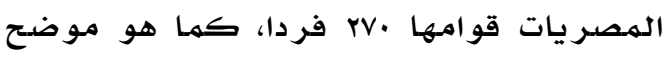

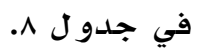

ويوضسح جدول ^ أن جميع الارتباطات بين

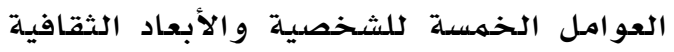
العالمية ارتباطات ضعيفة لجميع الفئات، حيث كان أعلى ارتباط موجب ذي مستوى آريان 


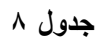

العلاقة بين الأبعاد الثقافية العالمية والعوامل الخمسة للثخصية

\begin{tabular}{|c|c|c|c|c|c|c|c|c|c|c|}
\hline \multicolumn{9}{|c|}{ معامل ارتباط بيرسون } & \multirow{3}{*}{ الأبعاد الثقافية } & \multirow{3}{*}{ والجنسية } \\
\hline \multicolumn{4}{|c|}{ الأبعاد الثقافية العالمية } & \multicolumn{5}{|c|}{ العوامل الخمسة للشخصية } & & \\
\hline تجنب عدم التيقن & 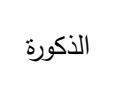 & الفردية & مسافة القوة & الانفتاح على الخبرات & العصابية & الاتبساطية & الإتقان & القبول & & \\
\hline \multirow{8}{*}{$" . .101$} & & & 1 & $\because . v_{0}$ & " " " & ..r. & $* * .1 \leq 1$ & $\because .1 \ldots$ & مسافة القوة & \multirow{10}{*}{ كويتيون } \\
\hline & & 1 & $" * 1 \cdot v$ & $* . . \wedge$. & $" * r \leqslant 4$ & $" . .|v|$ & $* * 111$ & " & الفردية & \\
\hline & 1 & $" * .009$ & $* * .119$ & $\ldots r \leq$ & $" *$ ".rT & $* * .1 \leq$ & " * & "ro. ro. & الذكورة & \\
\hline & $"$ ". . Y^ & $" . .1 \leq 7$ & $" \ldots 99$ & $\ldots 19$ & $" * .1 \leq 9$ & "*. .177 & $\because .7 \varepsilon$ & $\because \ldots 7 \varepsilon$ & تجنب عدم التيقن & \\
\hline & *". . r & 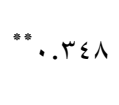 & ** . . sor & $" . .1 Y \wedge$ & $" \cdots \wedge \wedge$ & $" . .119$ & "... & $\cdots \wedge$ & التوجه طويل & \\
\hline & & & 1 & $\ldots r \wedge$ & ..Tr &..$\cdot r$ & $\ldots v$ & $\ldots \times 1$ & مسافة القوة & \\
\hline & & 1 & ה ה ". " & $" . .109$ & $* * .170$ & $* * * r \leq V$ & "*.rIV & $*$ *.r. & 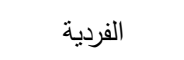 & \\
\hline & 1 & $* .001$ & $* * . . \leq \leqslant 0$ & $\ldots v_{1}$ & ..人r & ".lr. & " & $\because .0197$ & الذكورة & \\
\hline 1 & $* * \ldots$ & ". $\because Y \leq$ & $* *$ *.M & $\cdots \vee \vee q$ & $\cdots+r$ & $\because 1 \leq 1$ & $" . .11 \leq$ & $\cdots \wedge v$ & تجنب عدم التيقن & \\
\hline \multirow[t]{4}{*}{. .117} & $" . .0 Y \leq$ & $" . .779$ & ". trVA & ". .10r & $\cdot .1 \cdot 1$ & $.11 \mathrm{~V}$ & "..Ir & ". & التوجه طويل & \\
\hline & & & 1 &. .09 &.., $1 r$ & $\cdots 10$ & $\cdots 9$. & $\cdots 11$ & مسافة القوة & \multirow{5}{*}{ 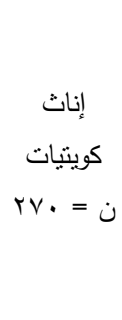 } \\
\hline & & 1 & $* * .011$ & $" . .179$ & $\ldots 90$ & $\ldots 7 \varepsilon$ & $\because .1 \leq r$ & $\ldots$ TV & الفردية & \\
\hline & 1 & $" . .7 r V$ & $* * .7 Y 1$ & $\cdots \wedge 1$ & $\cdots v V$ & $\cdots \leqslant r$ & $\cdots v v$ & $\cdots 71$ & 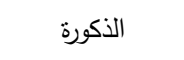 & \\
\hline 1 & $" . .|\wedge|$ & $" . .199$ & $" . .1 \leq 7$ & $\cdots \wedge$ & $\because 100$ & $\cdots \wedge 1$ & $" .1 \leq 1$ & 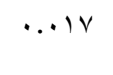 & تجنب عدم التيقن & \\
\hline \multirow[t]{4}{*}{ "*. .419} & $" \because \varepsilon \wedge q$ & $" . .094$ & **. . rqג & $" . .10 \mathrm{~V}$ & $* * ., \cdot .0$ & $\ldots 99$ & $* * .109$ & $\cdots \cdots$ & التوجه طويل & \\
\hline & & & 1 & $\cdots+17$ & $\ldots 99$ & ".lro & $\ldots \times q$ & ".1r4 & مسافة القوة & \multirow{3}{*}{ ذكور } \\
\hline & & 1 & $* * . \leqslant \wedge r$ & " & "* $\because r l$ & $\because 1 \leq 9$ & $* * .11$ & $\cdots 71$ & الفردية & \\
\hline & 1 & ". ". . & ". & $" . .1 \mathrm{VI}$ & $\because 1 \leq 1$ & $\ldots 79$ & $\cdots v V$ & $" . .17 \varepsilon$ & الذكورة & \\
\hline 1 & $* * \quad \cdot r \leq 1$ & $\because 1 r \varepsilon$ & $" . .109$ & $\cdots v V$ & $" . .411$ & $" . .1 \vee \wedge$ & $" . .1 \mathrm{~V}$ & $* . .17$. & تجنب عدم التيقن & ن = •. مصريون \\
\hline \multirow[t]{4}{*}{$\because 1 \leq}$. & $* * . . \leqslant T$ & $" * . \leqslant \vee 1$ & $* * . . \Sigma \vee \wedge$ & $\cdots r$ & $\because|r|$ & $\cdot .1 \cdot 1$ & $\cdots \leqslant 0$ & $\cdots 19$ & التوجه طويل & \multirow{6}{*}{ 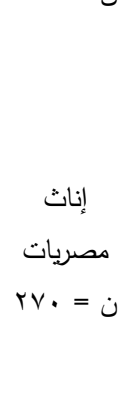 } \\
\hline & & & 1 & $\ldots 10$ & $\ldots r V$ & $\because .1 r v$ & $\ldots 9 \vee$ & $\ldots r \wedge$ & مسافة القوة & \\
\hline & & 1 & $* * .0 \ldots$ & $* . .170$ & $\ldots .0 \mathrm{~V}$ & $* * .101$ & $\because .1 \leq \varepsilon$ & $\cdots 10$ & الفردية & \\
\hline & 1 & ${ }^{* *} \cdot$ * r II & דוזי. " " & $" .197$ & $\because 1 \leqslant V$ & $\ldots+r$ & ". . roo & $\ldots 9 r$ & ال الذكورة & \\
\hline 1 & $" . .1 \wedge \varepsilon$ & $\ldots 9 \leq$ & $\ldots 10$ & $\cdots r \wedge$ & $\ldots \ldots$ & ".1 Tro & $\cdots 71$ & ..rr & تجنب عدم التيقن & \\
\hline$\ldots v 4$ & ". ". TVY & $" .0 \leq 47$ & ". $.09 \varepsilon$ & $" . . \mid \vee \wedge$ & $\cdots r \wedge$ & $* * .179$ & $* 1 \leq 7$ & $\cdots 1 \leq$ & التوجه طويل & \\
\hline
\end{tabular}

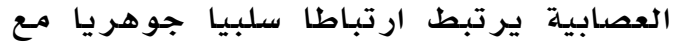

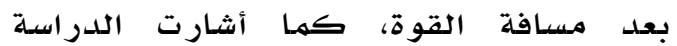
الحالية أيضا إلى أن العصابية تر تبط ارتباطا جوهريا إيجابيا مـع عل من الفردية و الذكورة و وتجنب عدم التيقن والتوجيه

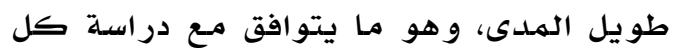

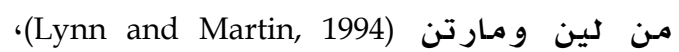

كما أنه لا توجد ارتباطات لعامل الانبساطية ذات دلالة جوهرية مـع الأبعاد الثقافية

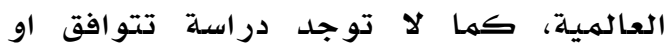

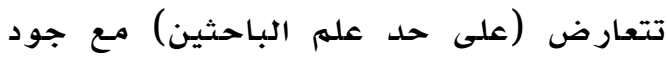
ارتباط سلبي بين الانبساطية وكل من تجنب عدم التيقن و التوجهه طويل المدىى. ومن نتائج الدراسلة الحالية، أن عامل 


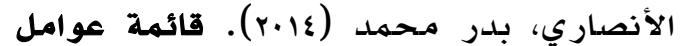
الشخصية الخمسة. المرجع في مقاييس

الشخصية. الكويت: دار الكتاب الحديث.

عبدالخالق، أحمد محمد (199£). الأبعاد الأساسية للشخصية الها، احملد الاسكندرية: دار

المعرفة الجامعية.

عبدالخالق، أحمد محمدد (.....). استخبارات

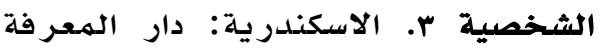

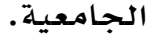

Allik, J., \& McCrae, R. R. (2004). Toward a geography of personality traits patterns of profiles a cross 36 cultures. Journal of Cross-Cultural Psychology, 35(1), 13-28.

Allport, G. W., \& Odbert, H. S. (1936). Trait-names: A psycho-lexical study. Psychological Monographs, 47(1), i-171.

Ardichvili, A., \& Kuchinke, K. P. (2002). Leadership styles and cultural values among managers and subordinates: a comparative study of four countries of the former Soviet Union, Germany, and the US. Human Resource Development International, 51, 99-117.

Barney, J. B. (2002). Strategic management: from informed conversation to academic discipline. Academy of Management Executive, 162, 53-57.

Cattell, R. B. (1943). The description of personality: basic traits resolved into clusters. Journal of Abnormal and Social Psychology, 384, 476-506.

Davies, H., \& Ellis, P. (2000). Porter's competitive advantage of nations: time for the final judgement? Journal of Management Studies, 37(8), 1189-1214.

Hofstede, G. (1980). Culture's consequences: International differences in work-related values. Beverly Hills, CA: Sage.

Hofstede, G. (1984). Culture's consequences: international differences in work-related values. Newbury Park, CA: Sage Publications.
وألك و ماكري (Allik and McCrae, 2004). كما لا توجد دراسـة تتوافق أو تتعارض

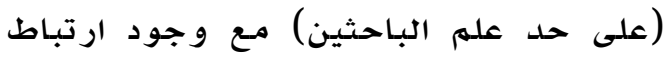
إيجابي بين العصابية و وكل مـن الفردية و التوجـه طويل الهدى. لئل

و أخيرا تشير الدراسة الحالية إلى أن عامل الانفتاح على الخبرات يرتبط ارتباطا سلبيا جوهريا مـع كل من أبعاد مسافة القوة

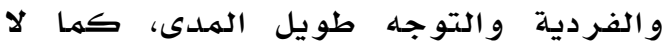

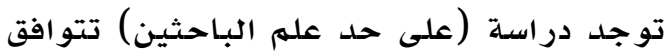

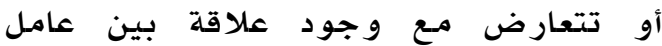
الانفتاح على الخبرات وبعد التوجله طويل

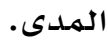

من ضهمن الأسباب التي جعلت الارتباطات بين

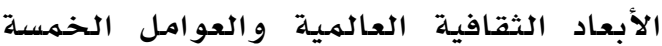
للشخصية ضعيفة ربها يكون ضعف دقة

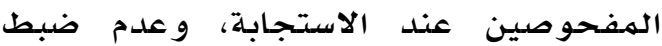
المتغيرات الدخيلة التي من المـمكن أن تغير الدير

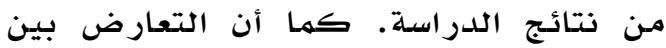

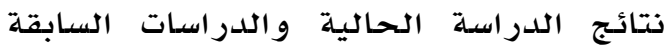
يرجـ إلى ارتفاع أو انخفاض أحد الأبعاد

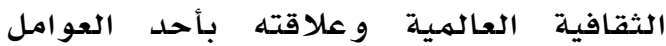
الخمسة للشخصيلة. كل ذلك يجعلنا نتريث قليلا في تأكيد النتائج المستخرجة، حتى

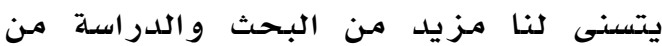
خلال المجتهعات العربية. ومـع ذلك كله كله، نستطيع أن نوقن بأنه توجد الند علاقة بينه

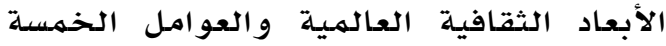

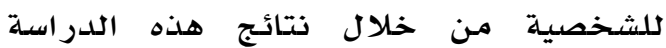
والدراسـات السـابقة، ومن مخلال الإطار النظري الذي عرضناه في مقدمـة من هذه

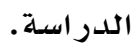
المراجع

\section{References}

$$
\begin{aligned}
& \text { الأنصاري، بدر محمدد (199v)). مدى كفاءة }
\end{aligned}
$$

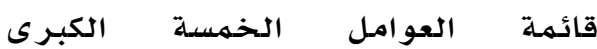

$$
\begin{aligned}
& \text { للشخصية في الهجتمـع الكويتي. دراسات } \\
& \text { نفسية، VY VY }
\end{aligned}
$$


Hofstede, G. (1991). Cultures and organizations - software of the mind. New York: McGraw Hill.

Hofstede, G. (2001). Culture's consequences: Comparing values, behaviors, institutions and organizations across nations $\quad\left(2^{\text {nd }}\right.$ ed.). Thousand Oaks: Sage Publications.

Hofstede, G. (2011). Dimensionalizing cultures: the hosted model in context. Online readings in psychology and culture, 21. Retrieved December 10, 2013, from http://dx.doi.org/10.9707/2307-0919.1014

Hofstede, G., \& Hofstede, G. J. (2013).Culture. In how did we acquire our collective programming? Retrieved November 25, 2013, from http://geerthofstede.nl/culture.aspx

Hofstede, G., Hofstede, G. J., \& Minkov, M. (2010). Cultures and organizations: software of the mind. (3 th ed). New York: McGraw-Hill.

Inkeles, A. \& Levinson, D. J. (1954). National character: The study of modal personality and sociocultural systems. In G. Lindzey \& E. Aronson (Eds.), The Handbook of Social Psychology IV (pp. 418- 506). New York: McGrawHill.

Jandt, F. E. (2009). An introduction to intercultural communication. (6 $6^{\text {th }}$ ed.). England: Sage Publications.

Kashima, Y., \& Kashima, E. S. (2003). Individualism, GNP, climate, and pronoun drop is individualism determined by affluence and climate, or does language use play a role? Journal of Cross-Cultural Psychology, 34 1, 125-134.

Pedersen, T., \& Thomsen, S. (1997). European patterns of corporate ownership: a twelve-country study. Journal of International Business Studies, 28,759-778.

Lynn, R., \& Martin, T. (1994). National differences for thirty-seven nations in extraversion, neuroticism, psychoticism and economic, demographic and other correlates. Personality and Individual Differences, 19 3, 403-406.
Naumov, A., \& Puffer, S. (2000). Measuring Russian culture using Hofstede's dimensions. Applied Psychology, 494, 709-718.

Roodt, T.K.G. (2003). Hofstede's VSM-94 revisited: is it reliable and valid. Journal of Industrial Psychology, 29 1, 7582

Steel , P., \& Taras, V. (2010). Culture as a consequence: A multi-level multivariate meta-analysis of the effects of individual and country characteristics on work-related cultural values. Journal of International Management, 16 3, 211-233.

Stull, J. B., Till, B. V. (1995, February 1014). Hofstede's dimensions of culture as measurements of student ethnocentrism: a quasi-experimental study. Paper presented at the Annual Meeting of the Western States Communication Association, Portland, California.

VanNess, R. K., Seifert, C. F., Franko, G., \& Buff, C. (2005). Hofstede's cultural dimensions: are individual differences important. International Journal of Business Research, 21, 161-166. 